\title{
A revision of the westwoodiine genus Pergaphaga (Hymenoptera, Ichneumonidae, Ctenopelmatinae)
}

\author{
Robert A. Wharton ${ }^{\dagger}$ Jonathan A. Cammack ${ }^{\ddagger}$, Patricia L. Mullins ${ }^{\S}$ \\ Department of Entomology, Texas A\&M University, College Station, Texas 77843 \\ † urn:lsid:zoobank.org:author:6AAF121C-A6DB-47B0-81EE-131259F28972 \\ $\ddagger$ urn:lsid:zoobank.org:author:B39E9D62-E537-4B3D-ACE0-F862D7709B55 \\ § urn:lsid:zoobank.org:author:CD6AA94D-E400-436A-B314-AC67A7A712F3 \\ Corresponding author: R. A. Wharton (rawbaw2@tamu.edu)
}

Academic editor: Gavin Broad| Received 6 November 2009 | Accepted 5 February 2010 | Published 25 February 2010

urn:lsid:zoobank.org:pub:3F8C1798-EC66-45A6-8E39-B2C3E3C38C95

Citation: Wharton RA, Cammack JA, Mullins PL (2010) A revision of the westwoodiine genus Pergaphaga (Hymenoptera, Ichneumonidae, Ctenopelmatinae). ZooKeys 37: 35-68. doi: 10.3897/zookeys.37.313

\begin{abstract}
Pergaphaga Gauld, a genus of ctenopelmatine Ichneumonidae endemic to Australia, is revised. The only previously described species, Pergaphaga nigra Gauld, is redescribed. Three additional species are newly described: Pergaphaga iangauldi Cammack \& Wharton, sp. n. from New South Wales, ACT, and Victoria, P. leaski Wharton, sp. n. from Victoria, and P. xanthops Wharton, sp. n. from New South Wales and ACT. Keys to species and a phylogenetic analysis are presented. Morphological terms are linked to the Hymenoptera Anatomy Ontology.
\end{abstract}

\section{Keywords}

Pergidae, Australia, parasitoid, multikey, ontology

\section{Introduction}

Townes (1970) described the tribe Westwoodiini as part of his revised classification of the Ctenopelmatinae, and included four genera (Westwoodia Brullé, Scolobatina Roman, Hypopheltes Cushman, and Megaceria Szépligeti), at that time known only from Australia. Gauld (1984) listed four characteristics shared by members of the Westwoo-

Copyright R.A.Wharton,J.A. Cammack, P.L. Mullins. This is an open access article distributed under the terms of the Creative Commons Attribution License, which permits unrestricted use, distribution, and reproduction in any medium, provided the original author and source are credited. 
diini and the more widespread but extralimital Scolobatini (which included Scolobates Gravenhorst, Onarion Townes, and Physotarsus Townes). On the basis of these shared features, Gauld (1984) combined all of the genera in a single tribe, the Scolobatini. Gauld (1984) removed considerable confusion regarding the Australian fauna by describing three new genera within his expanded concept of Scolobatini, transferring Megaceria Szépligeti, which had been misidentified by Townes (1970), to Euryproctini, and treating Scolobatina as a synonym of Westwoodia. Zhaurova and Wharton (2009) retained Westwoodiini and Scolobatini as separate tribes based on a reassessment of morphological characters, described one new genus, and removed Tasmabates Gauld from Westwoodiini. The Westwoodiini, as delimited by Zhaurova and Wharton (2009), is one of the smallest tribes of the ichneumonid subfamily Ctenopelmatinae, consisting of five genera but only nine described species (Townes 1970, Gauld 1984, Gupta 1987, Wharton et al. 2008, Zhaurova and Wharton 2009). Gauld (1984) indicated that this group of genera was endemic to Australia. Zhaurova and Wharton (2009) subsequently recorded a single specimen of one of these genera, Hypopheltes, from southern Papua New Guinea, a logical range extension for westwoodiines. Host records are available for all five genera, including Pergaphaga Gauld, and are summarized by Townes (1970), Gauld (1984), Wharton et al. (2008), and Zhaurova and Wharton (2009). All recorded hosts are in the subfamily Perginae of the sawfly family Pergidae (Hymenoptera).

When Gauld (1984) transferred Megaceria to Euryproctini, he noted that material previously misidentified as Megaceria represented an undescribed genus, which he then described as Pergaphaga. Townes (1970) and Short (1978), both using the name Megaceria, provided figures of the adult and larval mouthparts, respectively, of the type species of Pergaphaga, P. nigra Gauld. Carne (1969), under the name "?Hypopheltes," recorded P. nigra as a parasitoid of Perga affinis Kirby. Elliot and Bashford (1995) reared an undetermined species of Pergaphaga from Pergagrapta bella (Newman) in Tasmania. Although the plant host was not identified for this rearing record, Elliot and Bashford (1995) list Eucalyptus amygdalina Labill., E. pauciflora Sieber ex Spreng., and E. viminalis Dehnh. as the only plant hosts of $P$. bella in Tasmania. Aside from host records from label data reported by Gauld (1984) and repeated in Zhaurova and Wharton (2009), these are the only published data on the biology of Pergaphaga of which we are aware. Pergaphaga is thus far known only from southeastern Australia.

Gauld (1984) described only one species in Pergaphaga, but stated that he had seen three others that differed from the type species in coloration as well as venation. Gauld (1984) also stated that Pergaphaga is most closely related to Hypopheltes. Although Gauld (1984) did not provide any supporting data for this relationship, these two appear together in the last couplet of his key to Australian ctenopelmatine genera. Quicke et al. (2009) showed Pergaphaga as the sister-group to Hypopheltes in a larger analysis of ichneumonid relationships, but they did not have Dictyopheltes Gauld in their analysis. Zhaurova and Wharton (2009) noted that Pergaphaga more closely resembles Dictyopheltes than Hypopheltes, based on the more heavily sculptured body and the reduced glymma. Pergaphaga was paraphyletic relative to Dictyopheltes in 
the two strict consensus trees that Zhaurova and Wharton (2009) presented but they considered their analyses preliminary because so many species were undescribed. Our objective is to present comparative descriptions for all known Pergaphaga and thereby facilitate a better understanding of relationships among the Westwoodiini.

\section{Materials and methods}

Specimens. We borrowed specimens from the following institutions for use in this study: Australian National Insect Collection, Canberra (ANIC), The Natural History Museum, London (BMNH), Museum of Victoria, Melbourne (MVMA), and Queensland Museum, Brisbane (QMBA).

In the materials examined section under each species description, we record label data for the holotype exactly as they appear on the labels. We use a more standardized format for paratypes, additional specimens examined, and published data for specimens not examined. Detailed label data are available on the taxon pages via the website http://peet.tamu.edu/projects/8/public/site/ich/home/otus_by_taxon/27303.

Figures. Most images were acquired digitally using Syncroscopy's AutoMontage ${ }^{\bullet}$ software, in combination with a ProgRes 3008 digital camera mounted on a Leica MZ APO dissecting microscope. Figures 1 and 2 are modified from Townes (1969). All images were further processed using various minor adjustment levels in Adobe Photoshop such as image cropping and rotation, adjustment of contrast and brightness levels, color saturation, and background enhancement. Automontage images are available in color and high resolution at http://peet.tamu.edu/projects/8/public/site/ ich/home/otus_by_taxon/27303. Several of the images were previously published in a companion paper by Zhaurova and Wharton (2009).

Database management, digital dissemination, and ontology reference. Character by OTU matrices, illustrations, keys, and free-text diagnoses for morphospecies were assembled in $\mathrm{mx}$, a web-based content management system that facilitates data management and dissemination for taxonomic and phylogenetic works (e.g. Yoder et al. 2006). The $m x$ project is open source, with code and further documentation available at http://sourceforge.net/projects/mx-database/. Data pertinent to this work, including interactive matrices, specimen-level data, and a multiple entry key, are available at http://peet.tamu.edu/projects/8/public/site/ich/home/otus_by_taxon/27303.

Hyperlinks on terms reference anatomical entities in the Hymenoptera Anatomy Ontology (HAO, version "06:11:2009 15:48"; Yoder et al. 2009, see http://hymao. org). The HAO is a hierarchy of logically related entities (morphological parts). It allows multiple labels or terms (e.g. "propodeum") to point to the definition of a morphological feature. This allows synonymous or otherwise confusing labels to unambiguously reference a morphological feature. Note that hyperlinked terms may resolve to a feature that itself has another label. This does not imply synonymy or preference 
of a given label, it is simply how the internal logical structure of the ontology is managed. Hyperlinked terms point to the HAO as archived in BioPortal (Musen et al. 2008). Labels and terms have further meaning in the context of the larger ontology, as such their meaning is specific to the cited version. This versioning further allows for the precise encapsulation of meaning at a specific reference point. All versions of the HAO are archived at the OBO Foundry (http://obo.svn.sourceforge.net/viewvc/obo/ ontologies/trunk/HAO/, Smith et al. 2007).

Phylogenetic analysis. Based on Zhaurova and Wharton (2009), we used Dictyopheltes as the outgroup for analyzing relationships among the four known species of Pergaphaga. Two species of Dictyopheltes were used to encompass variation within the genus. Characters and character states are presented under the results and discussion section. Characters 4 (notauli), 9 (propodeum), and 14 (wing color) were included because of purported (Gauld 1984, Zhaurova and Wharton 2009) or potential value in supporting monophyly of either Dictyopheltes or Pergaphaga. We employed alternative character state codings for the propodeal carination, as explained below, to explore the impact of different hypotheses of character evolution on our overall assessment of relationships. We also explored the effect of adding and deleting a character as noted below under the results section. The morphological dataset was analyzed under parsimony with NONA using the WinClada interface (Nixon 2002). For comparison, we also used PAUP version 4.0b10. In all analyses, all multistate characters were treated as unordered. Bootstrap values were generated using 200 replicates, with 10 searches per replicate, holding 1 tree per search.

Terminology and measurements. Terminology (Figs 1-4) is essentially that used in Wharton et al. (2008) and Zhaurova and Wharton (2009), and is generally adapted from Gauld $(1991,1997)$ and more selectively from Townes $(1969,1970)$. We provide brief explanations in the following paragraphs where usage varies from or is in addition to that of Gauld (1991), or where elaboration may be helpful, a hyperlinked reference to the HAO.

Body length and antennal length, as given in the descriptions, are approximations of total length because of varying positions of the head and postmortem differences in telescoping and position of the metasoma. Wing length is measured from the base of the Costa to the apex of the wing and thus does not include the humeral plate and tegula. Abscissae are measured from the middle of their junctions. Length of the first flagellomere does not include the basal annellus, and all widths (flagellomeres and tarsomeres) are taken at midlength.

The face is the area between the anterior margin of the toruli and the anterior tentorial pits. We treat the face as separate from the clypeus (unlike Gauld 1991), with an epistomal sulcus, extending between the anterior tentorial pits, dividing the two. The antennal sockets are called toruli and the antennal tyloid on the lateral part of flagellomere 1 (Figs 14,15) is a distinctive patch of placoid sensilla (= placode or multiporous plate sensilla) used by Gauld (1984) to characterize his Scolobatini s. l. (= West- 

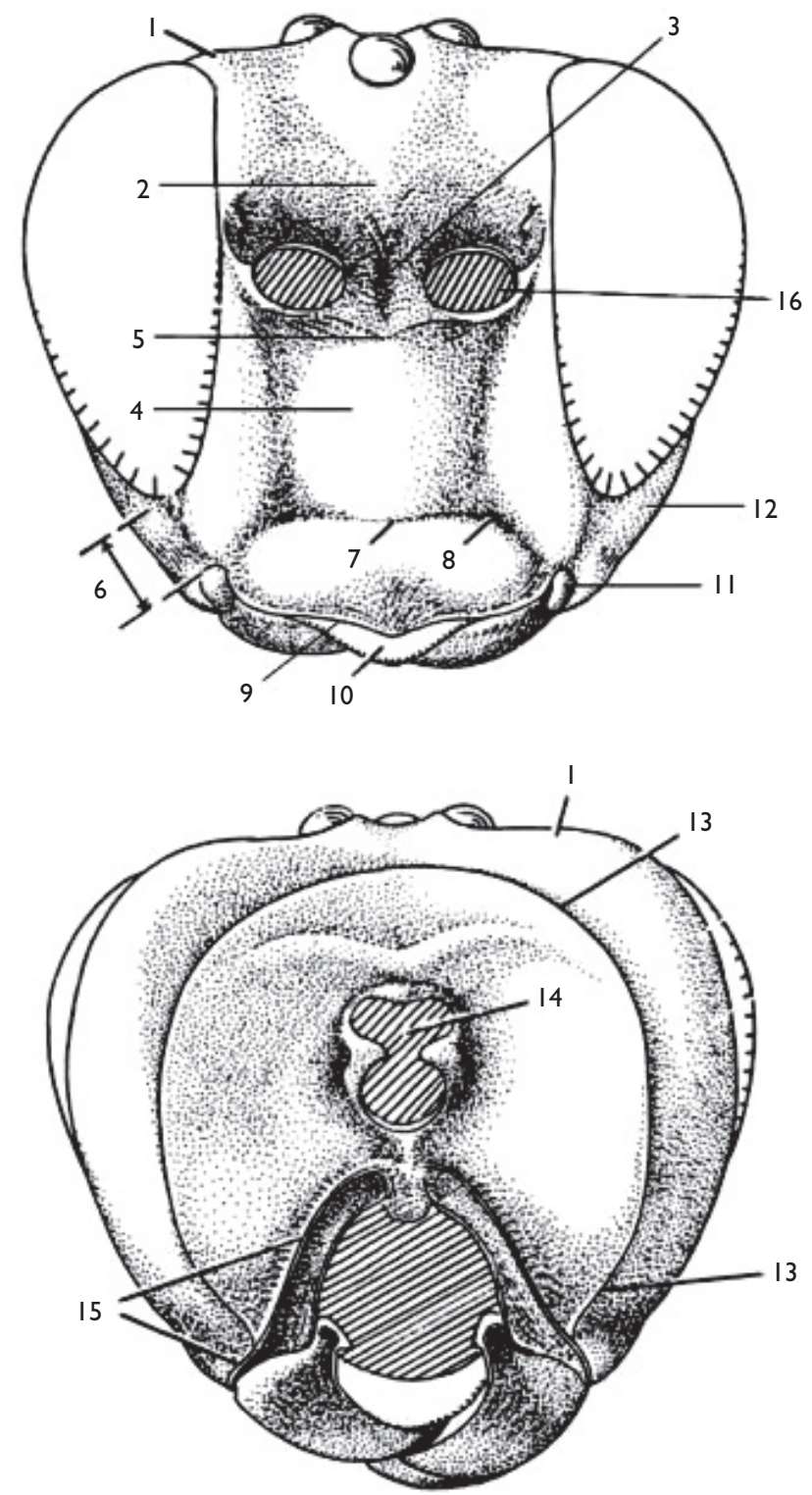

Figure I. Head of an ichneumonid (anterior and posterior views). I Vertex 2 Frons 3 Inter-antennal area (or ridge) 4 Face 5 Apical tooth on face $\mathbf{6}$ Malar space $\mathbf{7}$ Epistomal sulcus 8 Anterior tentorial pit 9 Clypeal margin 10 Labrum II Mandibular base 12 Gena 13 Occipital carina 14 Foramen magnum 15 Hypostomal carina 16 Torulus.

woodiini + Scolobatini of Zhaurova and Wharton 2009). An interantennal process (in the form of an elevated flange) extends posteriorly onto the frons from between the antenna in many westwoodiines and in two of the four species of Pergaphaga. Names for propodeal carinae (Fig. 2) and wing veins (Figs 3, 4) follow Gauld (1991). Gauld 


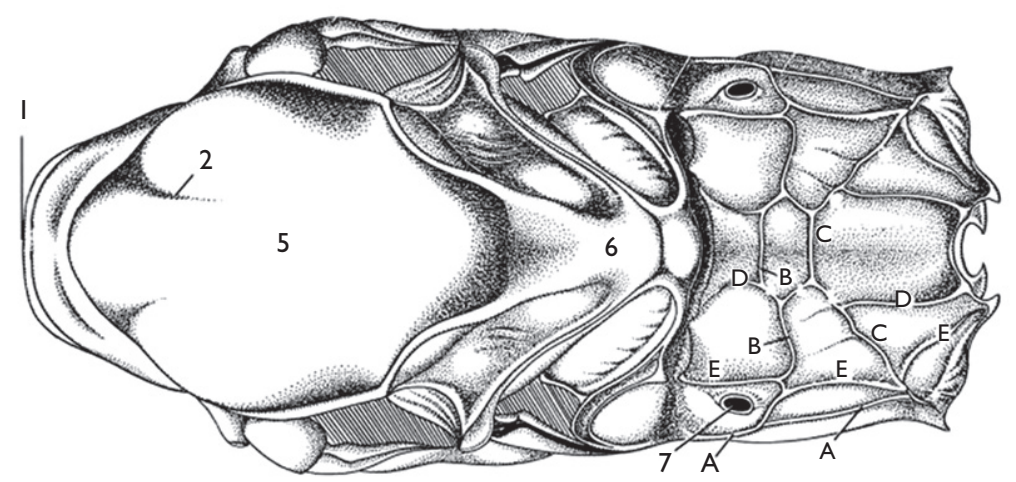

4

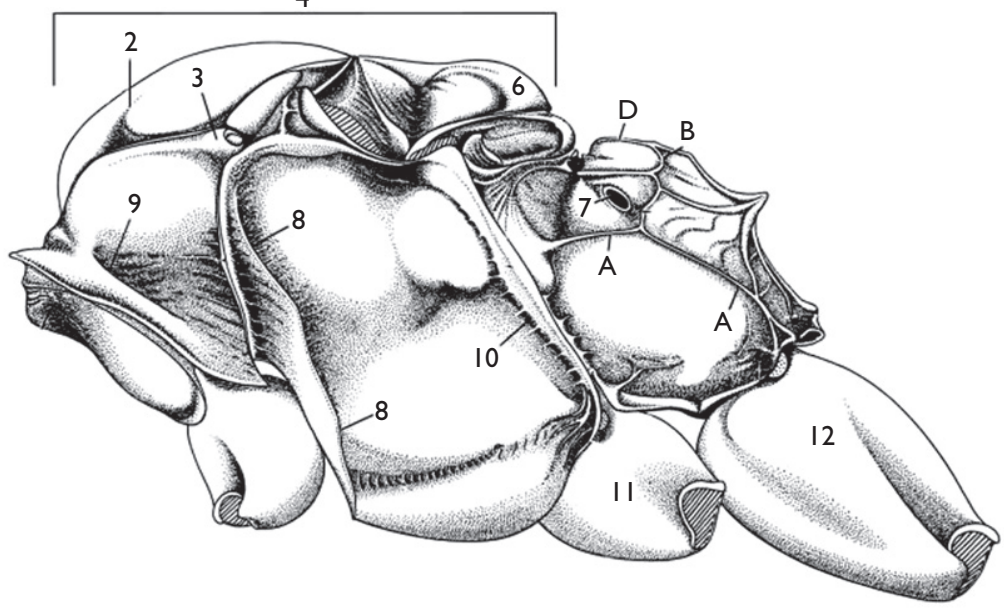

Figure 2. Mesosoma of an ichneumonid (dorsal and lateral views). I Anterior pronotal margin $\mathbf{2}$ Notaulus 3 Lateral corner of pronotum 4 Mesonotum 5 Mesoscutum 6 Scutellum 7 Propodeal spiracle 8 Epicnemial carina 9 Lateral groove of pronotum 10 Hind margin of mesopleuron II Mesocoxa. I 2. Metacoxa A-E Propodeal carinae: A Pleural carina B Anterior transverse carina C Posterior transverse carina D Median longitudinal carina E Lateral longitudinal carina.

$(1991,1997)$ did not label the first abscissa of $\mathrm{Cu} 1$ in the hind wing, but we have done so in Fig. 4 for clarification since the length of this abscissa relative to the length of $\mathrm{cu}-\mathrm{a}$ is used in the descriptions. Townes (1969) referred to the two abscissae combined as the nervellus. The mesopleuron in Pergaphaga and other westwoodiines has a broad, longitudinal impression for reception of the mid femora similar to the feature used by Townes (1970) to define the perilissine genera Opheltes Holmgren and Metopheltes Uchida. This is different from the sternaulus (Wharton 2006) and is referred to in the descriptions below as the mesopleural depression (best illustrated in Fig. 27, somewhat below the arrow), following the usage of Townes (1970). We treat the metasoma as consisting of the petiole (T1 + its sternite, S1) and the gaster (remainder of metasoma posteriorad petiole). Use of the term gaster follows Sharkey and Wharton (1997) and 


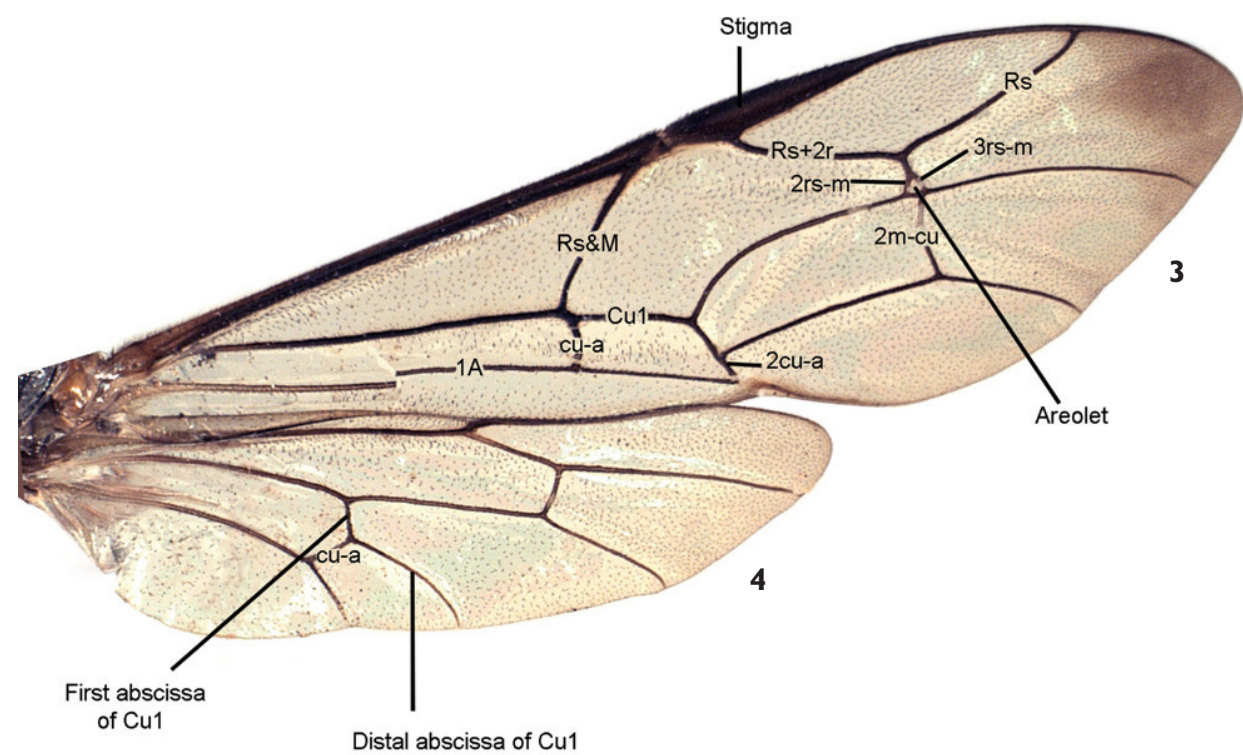

Figures 3-4. Wings of Pergaphaga iangauldi Cammack and Wharton, sp. n., paratype male, Murrumbeena. 3 Fore wing 4 Hind wing.

facilitates descriptions of color patterns. We refer to the apical, expanded part of T1 as the postpetiole following Gauld (1991). T2 and T3 refer to the second and third metasomal terga, respectively. We use the term epipleura for the enlarged, membranous region between the tergum and sternum on the first two metasomal segments, as described in some detail in Zhaurova and Wharton (2009). The definition of the following terms can be found in the HAO by following the associated hyperlinks: malar space ${ }^{1}$, orbital bands ${ }^{2}$, occipital carina ${ }^{3}$, hypostomal carina ${ }^{4}$, epicnemial carina ${ }^{5}$, mesoscutum ${ }^{6}$, notauli ${ }^{7}$, scuto-scutellar groove ${ }^{8}$, fore wing areolet $^{9}$, bulla $^{10}$, basitarsus ${ }^{11}$, trochantellus ${ }^{12}$, and glymma ${ }^{13}$. Note that the HAO is a hierarchy of classes, or things, and that multiple labels (or terms, e.g. "scuto-scutellar groove") can point to the same

http://bioportal.bioontology.org/visconcepts/40660/?id=HAO:0000503

2 http://bioportal.bioontology.org/visconcepts/40660/?id=HAO:0000673

3 http://bioportal.bioontology.org/visconcepts/40660/?id=HAO:0000653

4 http://bioportal.bioontology.org/visconcepts/40660/?id=HAO:0000413

5 http://bioportal.bioontology.org/visconcepts/40660/?id=HAO:0000292

6 http://bioportal.bioontology.org/visconcepts/40660/?id=HAO:0000575

7 http://bioportal.bioontology.org/visconcepts/40660/?id=HAO:0000647

8 http://bioportal.bioontology.org/visconcepts/40660/?id=HAO:0000919

9 http://bioportal.bioontology.org/visconcepts/40660/?id=HAO:0000147

10 http://bioportal.bioontology.org/visconcepts/40660/?id=HAO:0000184

11 http://bioportal.bioontology.org/visconcepts/40660/?id=HAO:0000178

12 http://bioportal.bioontology.org/visconcepts/40660/?id=HAO:0001033

13 http://bioportal.bioontology.org/visconcepts/40660/?id=HAO:0000378 
class, or definition of a part. For example, we prefer to use the label "scuto-scutellar groove" for the concept in the HAO which has the label "scutoscutellar sulcus".

\section{Results and discussion}

Characters and character states. The following characters and character states were used to assess relationships among the species of Pergaphaga in the phylogenetic analyses presented in Figs 47-48. Brief explanations are provided in most cases after descriptions of the character states.

1. Facial contour. (0) nearly flat; (1) slightly more elevated along eye margin, especially noticeable ventrally (Fig. 16).

The difference between the two character states is subtle, and difficult to assess without side by side comparisons. The difficulty is compounded by the fact that the face is entirely black in $P$. nigra but has yellow orbital bands, often contrasting with darker coloration medially, in the other three species of Pergaphaga.

2. Frons laterally. (0) distinctly elevated (Fig. 24); (1) flat or nearly so.

The anterior portion of the frons adjacent the compound eye is distinctly elevated in some species, with the elevation delimited medially by a weak to strong postantennal depression. This character co-varies with character 1 in most species, but not in P. nigra.

3. Frons medially. (0) without an interantennal process (= elevated flange) (Figs 23, 26), though sometimes with traces of a low, median carina; (1) with strongly elevated interantennal process/flange (Figs 21-22).

In some species of Pergaphaga, as in many other westwoodiines, an interantennal process in the form of an elevated median flange extends between the antennae onto the median part of the frons, where it usually bifurcates or trifurcates posteriorly. In westwoodiines, maximum elevation is usually immediately posteriorad the posterior margins of the toruli. In one of the species of Dictyopheltes, the median part of the flange is nearly absent, but the bifurcating arms are well developed (Zhaurova and Wharton 2009) and thus both species of Dictyopheltes have been coded as having strongly elevated flanges.

4. Notauli. (0) deeply impressed throughout, particularly well-developed at base (Fig. 27); (1) deeply impressed but incomplete, absent or nearly so at extreme base (Fig. 28).

5. Ventral part of mesopleural depression. (0) rugulose (Figs 29, 31); (1) distinctly punctate, at least medially (Fig. 30).

The mesopleural depression is usually extensively punctate in Pergaphaga, with the punctures tending to coalesce anteroventrally and the sculpture often becoming rugulose posteroventrally. The ventral part of the mesopleural depression is more heavily sculptured throughout in P. nigra (Fig. 29) but is clearly and distinctly punctate medially in the other three species (e. g. Fig. 30), with the punctures discrete but with punctation varying in density among species. 
6. Rounded lobe of mesopleuron forming anterodorsal margin of mesopleural depression. (0) finely, densely punctate (Figs 27, 29); (1) more deeply and less densely punctate.

7. Pleural carina. (0) complete, well-developed throughout, passing laterad propodeal spiracle, and easily distinguished from posterior portion of lateral longitudinal carina (Fig. 31); (1) incomplete or apparently so, extending as a distinct carina from anterior margin to spiracle, then either barely distinguishable or lost posteriorly (Fig. 30).

The pleural carina is always well developed anteriorly in Pergaphaga. In most species of Pergaphaga, however, it is greatly reduced posteriorly, either completely lost, replaced by a shallow groove, or present in the normal position as a very faint carina. In some specimens, the pleural carina appears to fuse with the lateral-most portion of the anterior transverse carina, curving medially around the ventral side of the spiracle to join the lateral longitudinal carina. This short transverse section is shown in Fig. 2 connecting the pleural and lateral longitudinal carinae, but the pattern of propodeal carinae in Pergaphaga is otherwise very different than what is shown in this figure. A clear carina is present in one of the three specimens of P. xanthops Wharton, sp. n., and it has been coded as variable for this reason.

8. Base of propodeum on either side of median depression. (0) heavily sculptured, usually rugose, more rarely deeply punctate (Fig. 33); (1) polished, smooth to finely shagreened (Fig. 34).

9. Pattern of propodeal carination. (0) strong, somewhat rugose transverse carina extending between spiracles (Figs 31, 33); (1) transverse carina partially replaced by weak, transverse striae (Fig. 32); (2) transverse carina not evident, replaced by weak, transverse striae (Fig. 34) (3) propodeum entirely rugose, with no transverse carinae (Fig. 35).

The distinctly elevated anterior transverse carina of $P$. nigra is variously replaced by weaker, irregular, transverse ridges in the other three species of Pergaphaga. In $P$. iangauldi Cammack and Wharton, sp. n., however, traces of a more distinct carina are often visible, and the basal median depression, in particular, is usually margined posteriorly by a carina. We coded $P$. iangauldi separately (state 1 , Table 1 ) for our initial analysis, but also performed an analysis with this species coded either as in $P$. nigra or as in $P$. xanthops + P. leaski Wharton, sp. $\mathrm{n}$.

10. Fore wing areolet. (0) large (Figs 36-37); (1) small (Figs 38-39); (2) absent (Fig. 40).

Examination of a series of specimens from Murrumbeena (see remarks under $P$. iangauldi), suggests that in Pergaphaga, state 2 is derived from state 1 . No such intermediates were apparent in Dictyopheltes (the outgroup), and character states were left unordered in all analyses.

11. Color pattern of flagellum. (0) flagellum entirely black; (1) black basally, pale apically (Fig. 12); (2) black apically, pale basally (Fig. 10).

12. Color pattern of hind tibia. (0) hind tibia without sharply contrasting pale basal ring; (1) tibia with sharply contrasting pale (yellow to light orange) basal ring (Fig. 9).

Pergaphaga nigra and the species of Dictyopheltes tend to have darker legs than the other three species of Pergaphaga, with the pale basal ring thus strongly contrasting. 
The hind tibia is yellow to orange in the other three species of Pergaphaga (Figs 42-44), though not always uniformly so.

13. Color pattern of female gaster. (0) all terga predominantly dark (Figs 5, 9, 41); (1) all terga predominantly brownish orange (Fig. 43); (2) at least some terga brownish orange, others predominantly black (Fig. 42).

In $P$. nigra, the petiole and all terga of the gaster are somewhat variable, but usually very dark brown to black anteriorly grading to dark reddish brown posteriorly, with pale apical margin, this margin tending to be broader in females than males. In the other three species of Pergaphaga, the gaster and parts of the petiole (especially postpetiole) are much lighter in coloration for the most part (Fig. 43). Pergaphaga iangauldi is slightly more variable (Fig. 42), and we have attempted to reflect this variation in the coding for this species. In those species for which more than one male was available for examination, males were somewhat more variable in coloration than females, but our sample is very small.

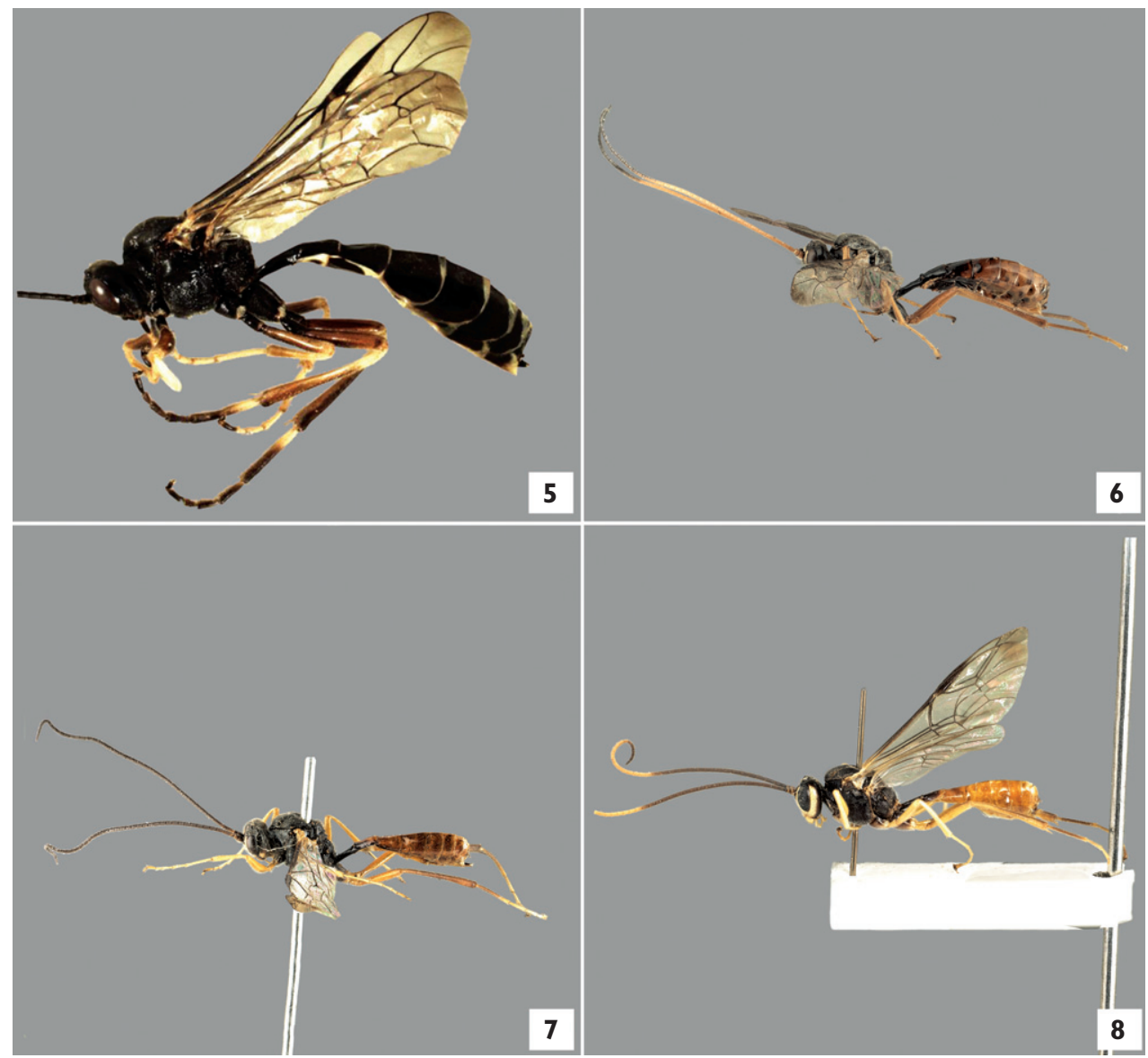

Figures 5-8. Pergaphaga spp., lateral habitus, female. 5 Pergaphaga nigra Gauld, paratype, Murrumbateman 6 Pergaphaga iangauldi Cammack and Wharton, sp. n., holotype 7 Pergaphaga leaski Wharton, sp. n., holotype 8 Pergaphaga xanthops Wharton, sp. n., holotype. 
14. Color pattern of fore wing. (0) weakly infumate anteriorly, fading to hyaline posteriorly, without infumate apical spot (Fig. 36); (1) hyaline with infumate apical spot (Fig. 39).

The infumate apical spot is present in all known specimens of Pergaphaga, as best illustrated in Fig. 39. The spot does not show up as prominently in some of the other figures because of background contrast.

15 Hind basitarsus, female. (0) Less than 9 times longer than wide; (1) More than 10 times longer than wide.

As indicated below in the redescription of $P$. nigra, there is some evidence for sexual dimorphism in proportions of the hind tibia, but the sample size is small.

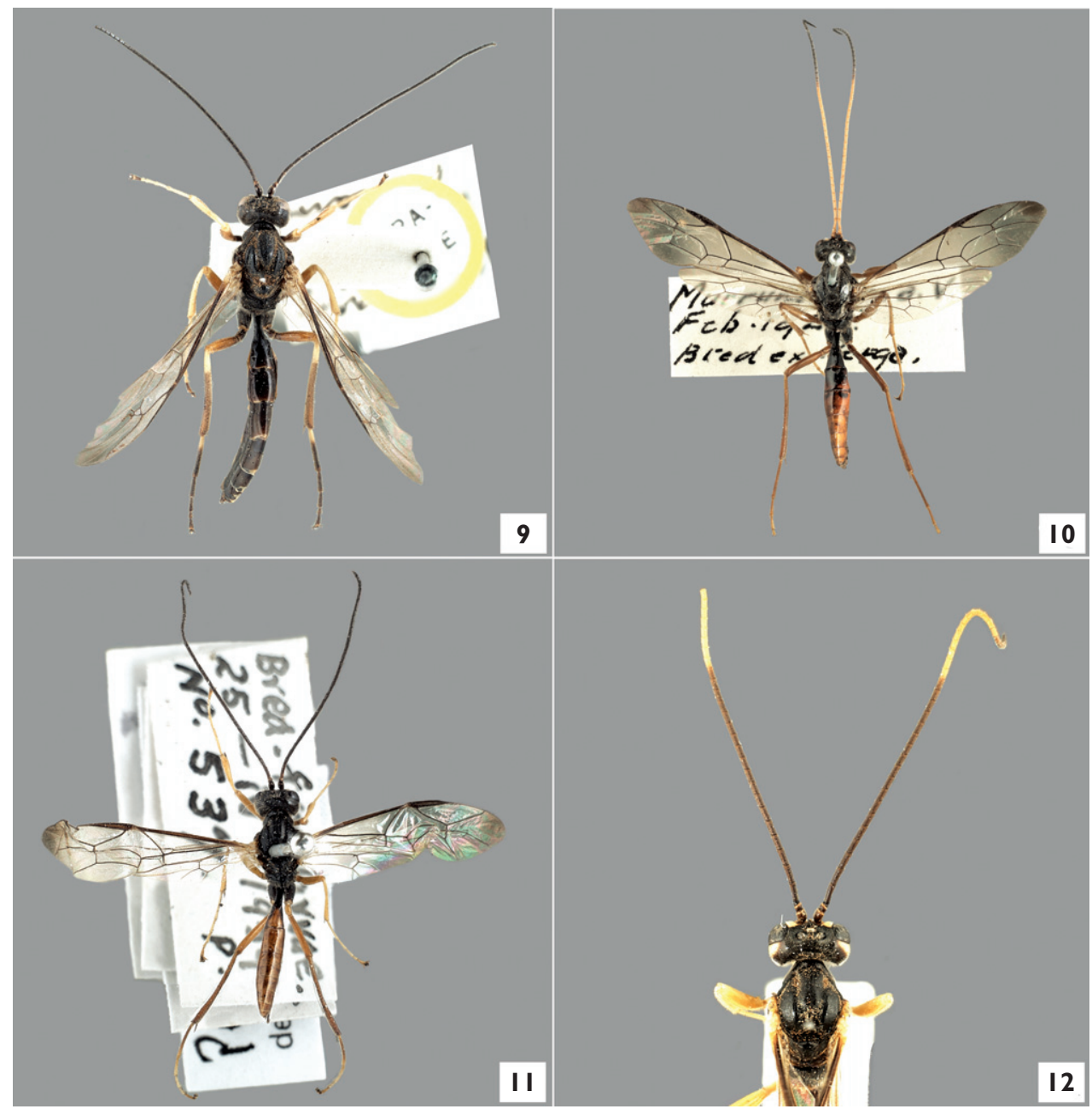

Figures 9-12. Pergaphaga spp., dorsal habitus, female. 9 Pergaphaga nigra Gauld, paratype, Canberra I 0 Pergaphaga iangauldi Cammack and Wharton, sp. n., holotype II Pergaphaga leaski Wharton, sp. n., holotype $\mathbf{2}$ Pergaphaga xanthops Wharton, sp. n., holotype. 
Assessment of relationships. All initial analyses produced a single tree (length $=21, \mathrm{CI}$ $=90, \mathrm{RI}=86$ ) with $P$. nigra as the sister group to the remaining species of Pergaphaga (Figs 47, 48). Heuristic and exact searches produced trees of the same length. The clade comprising $P$. xanthops $+($ P. iangauldi $+P$. leaski $)$ is characterized by weaker mesopleural and propodeal sculpture, longer hind basitarsus, and distinctly paler coloration. Loss of the interantennal flange and slight differences in facial features unite $P$. leaski and $P$. iangauldi relative to $P$. xanthops within this clade. The results suggest a single loss of the interantennal flange, but a complete loss followed by a gain of the fore wing areolet. The homoplasy resulting from minor incongruencies among characters is reflected in the bootstrap values shown in Fig. 48. Bootstrap values shown in Fig. 48 were generated using WinClada. Those generated via PAUP were equal to or very slightly higher for the $P$. xanthops $+($. iangauld + P. leaski) clade and the P. iangauld + P. leaski clade. There was virtually no effect when changing the coding of the propodeum in $P$. iangauldi to match that of $P$. xanthops and $P$. leaski. When the coding was changed so that $P$. iangauldi had the same character state as $P$. nigra, the relationships remained the same, but bootstrap support values for the $P$. iangauld + P. leaski clade not surprisingly dropped.

We were hesitant about using the epipleura as a character in our analyses despite the possibility that it may be phylogenetically informative (Townes 1970, Gauld 1984, 1997, Zhaurova and Wharton 2009). As noted by Zhaurova and Wharton (2009), there are problems in interpretation of this feature because its appearance varies with state of preservation. The epipleura appear to be better developed in $P$. nigra and $P$. iangauldi than in the other two species, though this is not evident in all specimens. In $P$. leaski and $P$. xanthops, which are smaller species, the epipleura are generally not apparent, or in some specimens only weakly indicated, but we are unable to determine if this is simply a preservation artifact. For these reasons, we excluded the epipleura from our initial analyses and delineation of characters and character states. We did, however, explore the effect this character might have on assessment of relationships within Pergaphaga by coding it for a separate PAUP analysis, assuming no preservation artifacts. Relationships remained the same as those presented in Fig. 48, but support for the $P$. iangauld $i+$ P. leaski clade was greatly reduced.

There is relatively weak support for the monophyly of Pergaphaga, though bootstrap values were distinctly higher ( 75 vs. 58 ) in the PAUP analysis. However, demonstration of the monophyly of Pergaphaga was not a goal of this analysis. Monophyly of Pergaphaga and Dictyopheltes is treated in the next section, under the diagnosis for Pergaphaga.

\section{Descriptive taxonomy}

\section{Pergaphaga Gauld, 1984}

Pergaphaga Gauld, 1984: 231. Type species: Pergaphaga nigra Gauld, 1984 by monotypy and original designation. 
Pergaphaga: Gupta 1987: 355 (catalog); Yu and Horstmann 1997: 455 (catalog); Zhaurova and Wharton 2009: 34, 39-41, 62-65, 67, 69-77 (key to genera of Westwoodiini, redescription, figures, relationships).

Megaceria auct. (misidentified, not Megaceria Szépligeti, 1908): Townes 1970: 57-58, 224 (key, description, figure); Short 1978: 62-64, 259 (larva).

Diagnosis: Clypeus similar in outline in all species (Figs 17-20), with ventral margin broadly truncate or nearly so medially, sharply angled dorsally near lateral margin. First flagellomere with large tyloid containing numerous ( $>20)$ placoid sensilla (Figs 14, 15). Occipital and hypostomal carinae meeting ventrally well before base of mandible (Fig. 25). Mesoscutum densely punctate throughout; notauli deep throughout, including at anterior margin (Fig. 27), V-shaped, converging posteriorly in broad, shallow depression separated from scuto-scutellar groove by a weak elevation; mesopleural depression broad and distinct. Propodeum varying from partially and weakly to extensively and strongly rugose (Figs 33-34), but always with some carination visible. Inner hind tibial spur almost twice length of outer spur. Fore wing $2 \mathrm{~m}$-cu with a single bulla. Petiolar tergosternal sulcus located ventrally when viewed in profile. Glymma represented by a shallow dorsal depression anteriorly (Fig. 45). S1 extending more than half distance to spiracle, usually to or nearly to level of spiracle. Metasomal segments 1-2 and more rarely 3 with epipleura bare and membranous when visible, often collapsed and extending outwardly as fleshy protrusions in dried specimens. Female gaster laterally compressed apically from middle of T3. In lateral view, cerci attached ventrad middle of posterior aspect of gaster. All four of the known species have hyaline wings with an infumate spot at the tip of the fore wing.

Pergaphaga can be differentiated from other Ctenopelmatinae by a combination of characters specific to Westwoodiini, including fore wing RS+2r arising from or near the base of the stigma (Figs 36-40), cerci of females ventrally displaced, and first flagellomere with a large tyloid laterally. The tyloid is in the form of a bare patch of numerous (>20), irregularly arranged placoid sensilla (Figs 14-15).

As noted by Zhaurova and Wharton (2009), Pergaphaga is perhaps the least readily characterized of the known westwoodiines, and the species most closely resemble those currently placed in Dictyopheltes. The species of Pergaphaga and Dictyopheltes are characterized relative to other westwoodiine genera by the shallow to indistinct glymma (Fig. 45), with the petiole thus resembling that of certain Euryproctini. Gauld (1984), in fact, stated that Pergaphaga and Dictyopheltes lacked a glymma, and he used this feature in his key to the Australian genera of ctenopelmatines. A glymma-like depression is present in nearly all individuals that we examined, but is much different in appearance than the deeper glymma of Westwoodia, Gauldia, and Hypopheltes. It is narrow, shallow, and almost slit-like in some specimens, and never as distinct as it is in these other genera.

The sternite of the petiole is longer in Pergaphaga relative to that in Dictyopheltes. Additionally, the species of Pergaphaga are less heavily sculptured than those of Dictyopheltes, and retain at least some visible carination on the propodeum (Figs 33- 
34). The most distinctive feature of the propodeum is the presence of a straight to very weakly arched transverse carina or series of low, transverse ridges extending between the propodeal spiracles that is not found in other westwoodiines, and which is variously developed in the new species described below. The monophyly of Pergaphaga is thus largely supported by the patterns of propodeal carination and wing coloration.

Monophyly of Dictyopheltes is supported primarily by two character states: notauli absent at base and propodeum rugose, without distinct carinae (Gauld 1984, Zhaurova and Wharton 2009).

Biology. The species of Pergaphaga have been reared from pergine sawflies feeding on Eucalyptus, and specifically from Perga affinis (Carne 1969), Pergagrapta bella (Elliot and Bashford 1995) and Pergagrapta gravenhorstii (Westwood). The latter record is based solely on label data from the type series of $P$. leaski. There are collection or rearing records from every month except September and November, but the vast majority are from February through June.

Pergaphaga is known only from southeastern Australia, ranging from South Australia, through Victoria and north about midway through New South Wales. In addition to the specimens recorded below under the species descriptions there are published records of Pergaphaga from Tasmania (Elliot and Bashford 1995), but we have not seen this material. The specimens of $P$. nigra labeled as South Australia (BMNH) have no additional data, and we are unable to pinpoint the locality further.

Remarks. Pergaphaga is similar in size and general appearance to species of Megaceria, a more commonly encountered ctenopelmatine in the tribe Euryproctini (Gauld 1984). Both are Australian endemics, and the two have been confused in the past, prior to the detailed study of the Australian fauna by Gauld (1984). The species of Megaceria lack the distinct tyloid at the base of the outer side of the first flagellomere. The first flagellomere also tends to be longer in Megaceria, with RS generally arising more distally from the stigma and terminating closer to the wing tip. Additionally, the petiole is more completely tubular in Megaceria, with no obvious sulcus between the fused tergum and sternum, the spiracle is more anteriorly displaced, and there is a broader, more distinct bridge separating the foramen of the petiole from the coxal cavities. The shape of the forewing areolet is distinctive in Megaceria, unlike the various forms seen in Pergaphaga. In Megaceria, ornamentation on the frons varies, as does the development of lateral carinae on the scutellum and there's an unusual amount of variation in the trough and associated carinae and projections along the margin of the propodeum and metanotum. According to Gauld (1984), there are three described species of $\mathrm{Meg}$ aceria and at least 10 undescribed species.

\section{Key to species of Pergaphaga}

(multiple entry key available at: http://peet.tamu.edu/projects/8/public/clave/list)

1. Face black, without yellow orbital bands (Fig. 17); hind tibia dark with contrastingly pale (yellow to orange) ring basally (Fig. 9); base of propodeum 
heavily sculptured (Fig. 33); hind basitarsus of females less than 9 times longer than wide; fore wing areolet large (Fig. 37) ..................... P. nigra Gauld

- $\quad$ Face either entirely or almost entirely yellow (Fig. 20) or dark medially with yellow orbital bands (Figs 18-19); hind tibia orange to yellow, without obviously contrasting pale basal ring (Figs 42-44); base of propodeum polished, unsculptured (Fig. 34); hind basitarsus more than 10 times longer than wide; fore wing areolet nearly always small or absent (Figs 38-40) 2

2. Frons medially with elevated flange extending posteriorly from between antennae (Fig. 22); antenna dark basally, yellow to orange distally, with apical flagellomeres often black

P. xanthops Wharton sp. $\mathrm{n}$.

- $\quad$ Frons medially without elevated flange (Figs 23, 26); antenna either entirely black, or orange basally and black apically..... 3

3. Antenna entirely black (Fig. 11) P. leaski Wharton, sp. n. Antenna partly yellow to orange over at least basal half (Fig. 10)

P. iangauldi Cammack \& Wharton, sp. n.

\section{Pergaphaga nigra Gauld}

Figs 5, 9, 13, 17, 21, 24, 27, 29, 31, 33, 37, 41, 45, 46

Type locality. Australia, New South Wales, Murrumbateman, -34.967S, 149.033E.

Type material. Holotype. Female (ANIC), Australia, New South Wales, Murrumbateman, emerged III.1974 ex. Perga cocoon collected III.1973, R.B. McInnes [not seen]

Material examined. Paratypes: 6 females, 5 males, same data as holotype except emergence dates of 5.III, 2.VI., and 8.V.1973 and 21.II, 27.II., and 8.III.1974 (ANIC, BMNH); ACT, 1 female, Canberra, 12.V.1959, P.B. Carne (ANIC); 2 males, Duntroon, emerged 8-22.V.1960, parasite of Perga affinis (ANIC, BMNH); NEW SOUTH WALES, 1 male, Cookardinia, emerged 29.II.1960, ex culture 223, parasite of Perga affinis (BMNH); SOUTH AUSTRALIA, 2 females, no additional data (BMNH); VICTORIA, 2 females, Avoca, 220, emerged 10.VI.1957, parasite of Symphyta on Eucalyptus sp., M.F. Leask (BMNH).

Other specimens examined: ACT, 1 female, Canberra, 24.IV.1959, W. Vestjens (MVMA); 10 females, 2 males, Duntroon, emerged 8-22.V.1959 and IV-V.1960 from $P$. affinis cocoons collected 1958, P.B. Carne (ANIC); 2 females, same data except cocoons collected 24.II.1958, dissected 28.II.1959; VICTORIA, 1 male, $6.6 \mathrm{mi}$ W. of Bonnie Doon, 7.III.1973, R.S. McInnes, emerged ex. Perga cocoons 31.I.1975 (ANIC); 1 male, Hamilton, 10.X.1947, G. Stephens, collection A. N. Burns (MVMA); 1 female, 15 mi ESE Wangaratta, emerged 16.VII.1974 ex Perga cocoon collected 8.III.1973, R.S. Mclnnes (ANIC); 1 female, no locality, ex culture, emerged 25.VIII.1934, vide 20 (BMNH); 1 male, no additional data (MVMA).

Description. Female (Figs 5, 9). Length of body (exclusive of antenna) 12.5$21.3 \mathrm{~mm}$; of fore wing $11.0-15.7 \mathrm{~mm}$; of antenna $15.0-20.0 \mathrm{~mm}$. 


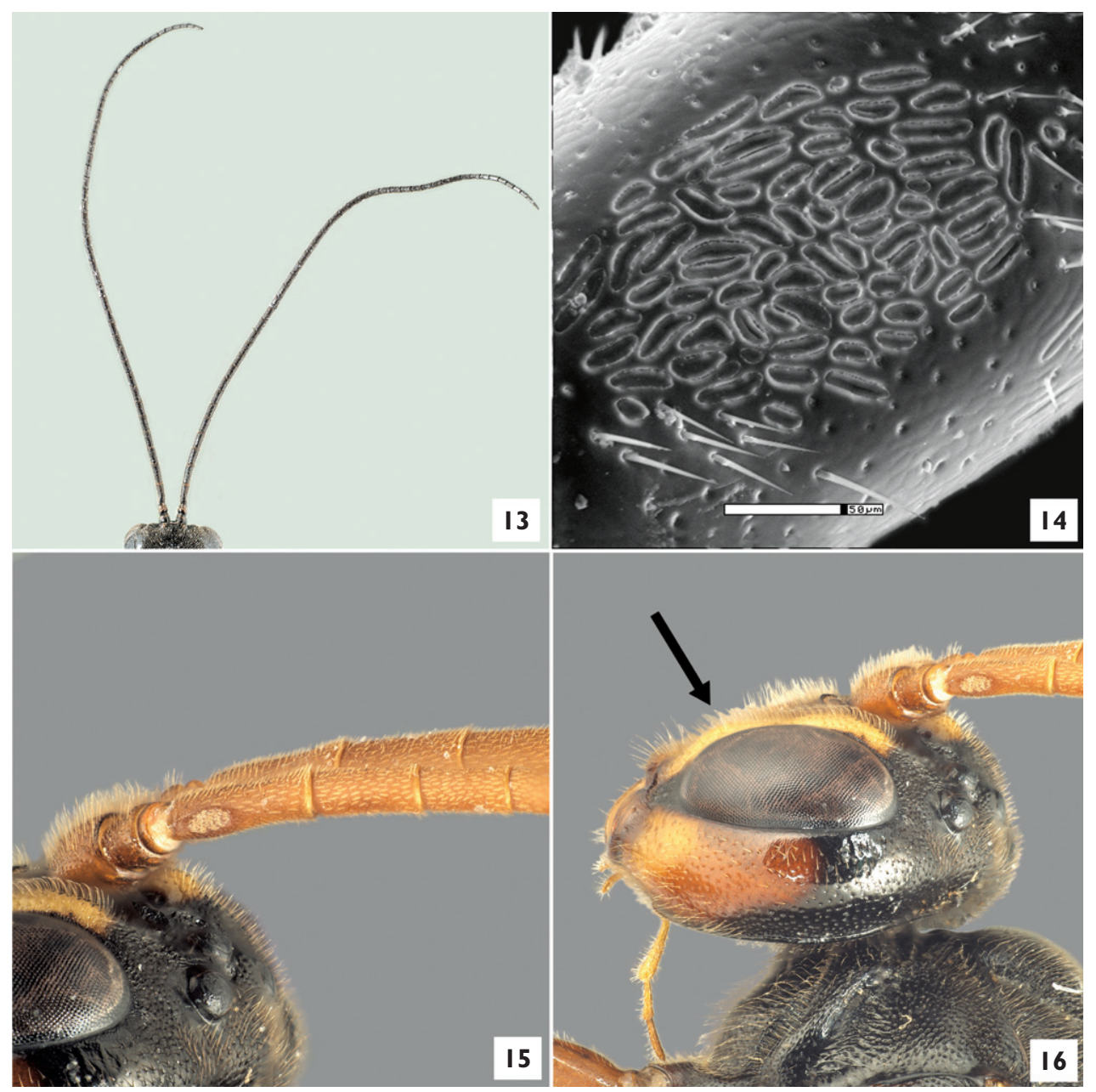

Figures 13-16. Pergaphaga spp., antenna and tyloid, female. 13 Pergaphaga nigra Gauld, antenna, nonparatype from Duntroon 14 Pergaphaga iangauldi Cammack and Wharton, sp. n., paratype, Murrumbeena, SEM of tyloid 15 Pergaphaga iangauldi Cammack and Wharton, sp. n., paratype, Canberra, relative size of tyloid and basal flagellomeres $\mathbf{1 6}$ Pergaphaga iangauldi Cammack and Wharton, sp. n., paratype, Canberra, arrow $=$ weakly bulging region of face.

Head. Clypeus (Fig. 17) 2.5-2.7 times as broad as long; slightly undulating; convex dorsomedially and along midline, impressed ventrolaterally, except raised and thickened at extreme lateral margin; ventral margin broadly truncate, slightly thickened medially; surface punctate and weakly rugulose on shagreened background, punctures coalescing, especially ventrally; epistomal sulcus indistinct. Malar space 0.6-0.7 times basal width of mandible, coarsely granular and shagreened. Lower gena deeply and densely punctate on finely shagreened background, becoming more sparsely punctate and polished dorsally, upper gena with punctures separated by 2-3 times their diameter, more densely punctate along occipital carina, more sparsely punctate adja- 


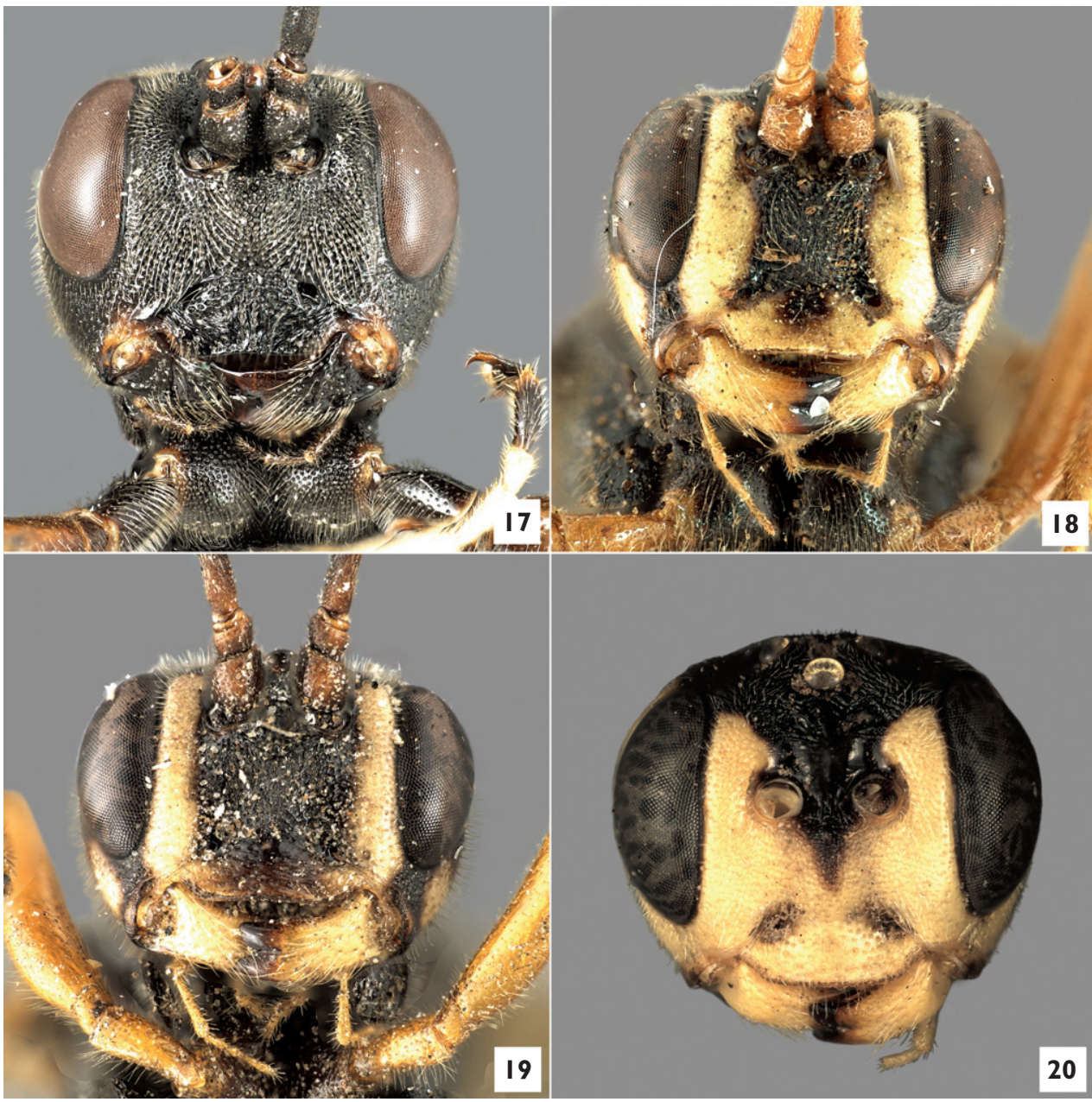

Figures 17-20. Pergaphaga spp., face, female. 17 Pergaphaga nigra Gauld, paratype, Murrumbateman 18 Pergaphaga iangauldi Cammack and Wharton, sp. n., holotype 19 Pergaphaga leaski Wharton, sp. n., holotype 20 Pergaphaga xanthops Wharton, sp. n., holotype.

cent eye at mid eye height. Face (Fig. 17) deeply and densely punctate, varying from rugose punctate to more densely granular rugose medially, surface slightly undulating transversely, weakly elevated medially, distinctly depressed near ventrolateral margin of toruli, nearly flat between anterior tentorial pit and eye. Frons with median, elevated flange (Fig. 21) extending posteriorly beyond posterior margin of toruli, bifurcating posteriorly, the resulting depressions between flange and toruli and between bifurcating arms and median ocellus polished and often weakly striate; frons densely granular on flattened portion between ocellar field and eye, rugose punctate on distinctly elevated portion between antenna and eye (Fig. 24). Antenna with 40-46 flagellomeres; first flagellomere at most 1.2 times longer than second, 3.0-3.7 times longer than wide, second flagellomere 2.5-3.1 times longer than wide, tenth 1.8-2.2 times longer 

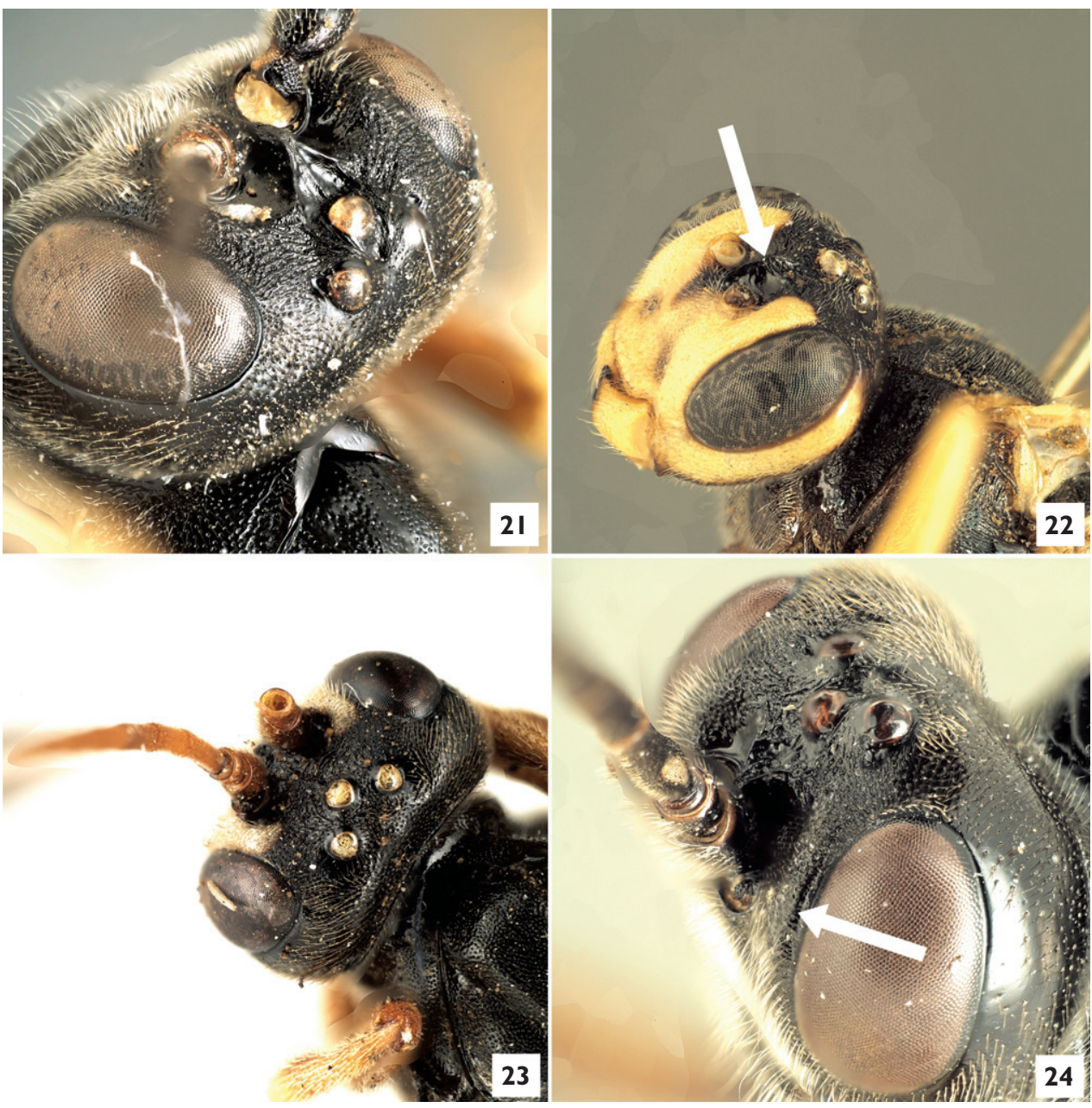

Figures 21-24. Pergaphaga spp., head, female. 2 I Pergaphaga nigra Gauld, showing interantennal flange extending onto frons, non-paratype from Duntroon 22 Pergaphaga xanthops Wharton, sp. n., holotype, arrow = interantennal flange extending onto frons 23 Pergaphaga iangauldi Cammack and Wharton, sp. n., paratype, Murrumbeena, showing absence of interantennal flange $\mathbf{2 4}$ Pergaphaga nigra Gauld, paratype, Murrumbateman, arrow = lateral bulge on frons.

than wide; tyloid of first flagellomere large, oval, extending $0.25-0.35$ length of first flagellomere.

Mesosoma. Pronotum laterally densely punctate (Fig. 27). Mesopleural depression rugulose punctate ventrally (Fig. 29), the punctures large, deep, coalescing; rounded lobe forming anterodorsal margin of mesopleural depression very finely, densely punctate, the punctures discrete but often touching or nearly so, much smaller than punctures on ventral part of mesopleural depression. Scutellum coarsely punctate. Posteromedian plate of metanotum densely, coarsely punctate to rugose punctate, never polished. Metapleuron medially densely rugose to rugose punctate. Propodeum 

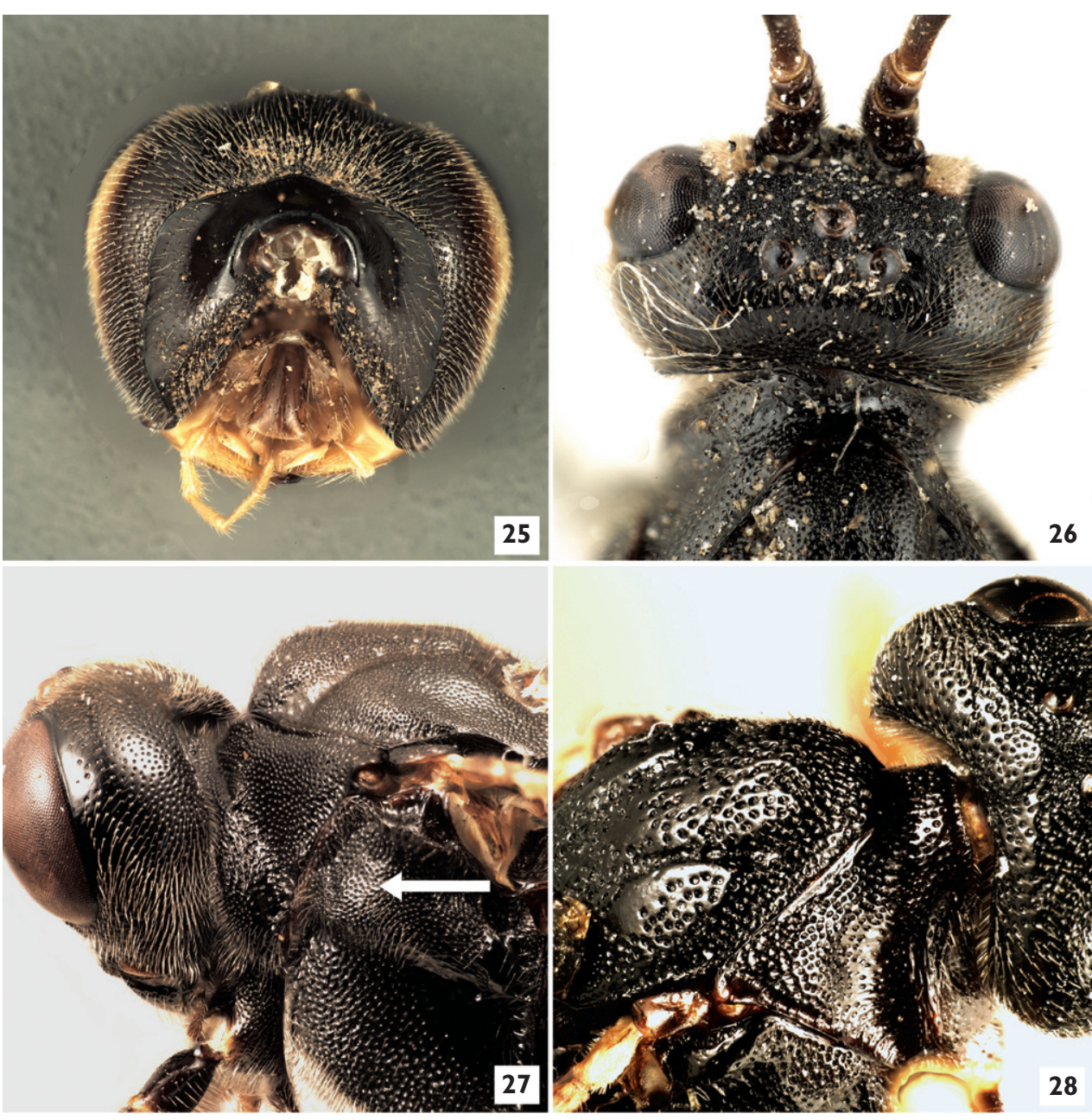

Figures 25-28. Head and thorax 25 Pergaphaga xanthops Wharton, sp. n., holotype, back of head showing occipital and hypostomal carinae meeting above base of mandible $\mathbf{2 6}$ Pergaphaga leaski Wharton, sp. n., holotype, top of head $\mathbf{2 7}$ Pergaphaga nigra Gauld, paratype male, Murrumbateman, showing notauli deep at extreme base; arrow = sculpture on anterior bulge above mesopleural depression 28 Dictyopheltes robustus Gauld, male, showing notauli incomplete, not extending to extreme base.

in profile (Fig. 31) with anterior and sharply declivous posterior fields distinctly separated by prominent anterior transverse carina extending between spiracles, the carina somewhat irregular, often rugose medially; base of propodeum, on either side of median depression, heavily sculptured as in surrounding areas (Fig. 33); pleural carina complete (Fig. 31): strongly elevated anterior portion extending posteromedially toward spiracle, then angled posteriorly near spiracle, less strongly elevated posteriorly, never touching spiracle; lateral longitudinal carina distinct posteriorly, absent or difficult to distinguish anteriorly; lateromedian portions of posterior transverse carinae often weakly indicated as elevated rugosities, forming a low to prominent tubercle at 


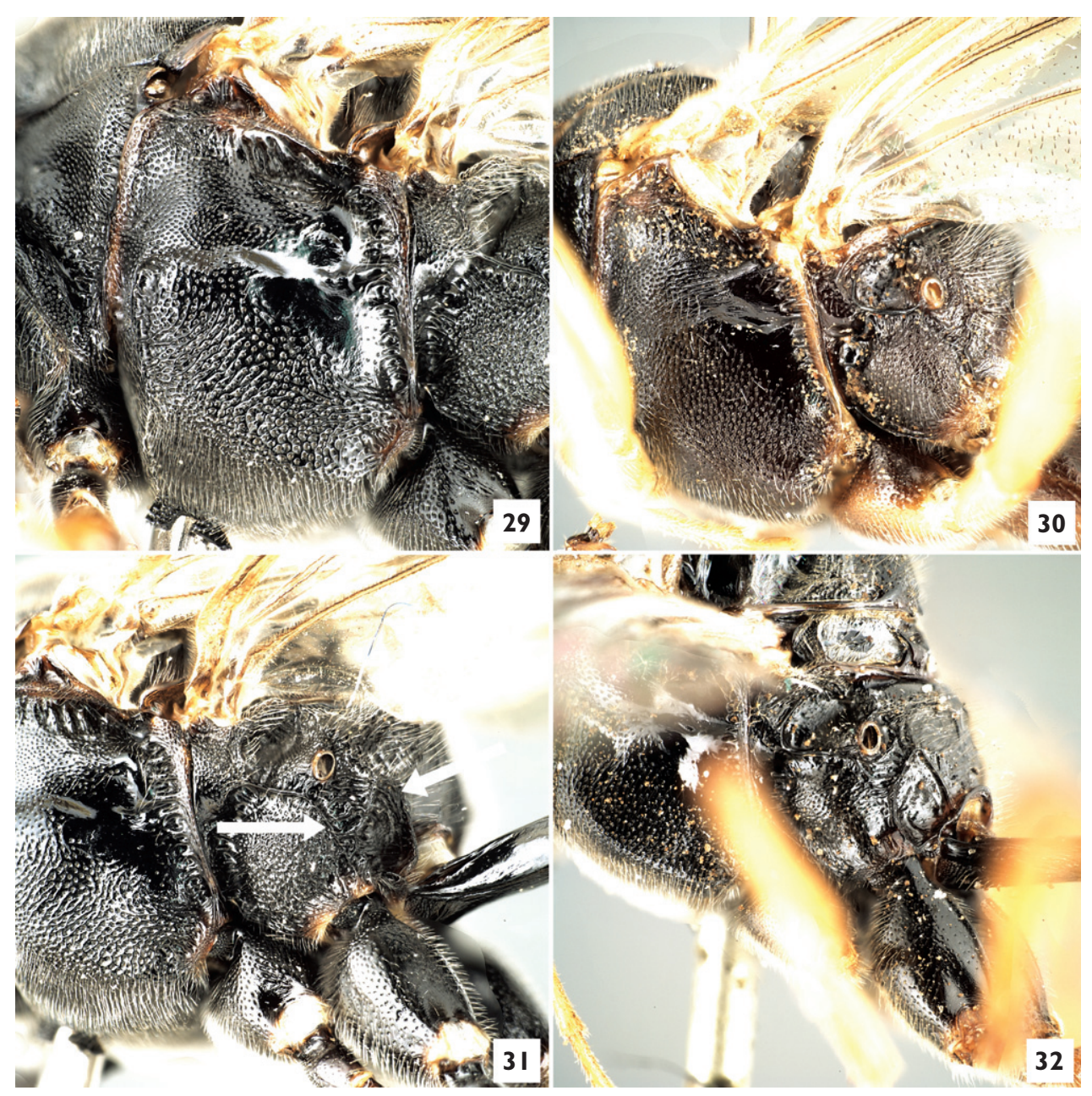

Figures 29-32. Pergaphaga spp., mesosoma, female. 29 Pergaphaga nigra Gauld, paratype, Murrumbateman 30 Pergaphaga xanthops Wharton, sp. n., holotype 31 Pergaphaga nigra Gauld, paratype, Murrumbateman, left arrow $=$ posterior portion of pleural carina, right arrow $=$ tubercle at junction of propodeal carinae 32 Pergaphaga iangauldi Cammack and Wharton, sp. n., paratype, Murrumbeena.

junction with lateral longitudinal carina; a longitudinal carina usually present along midline posteriorly. Hind basitarsus 7.2-8.7 times longer than wide. Fore wing areolet broad, rhombic, petiolate above, the stalk less than length of areolet (Fig. 37); $2 \mathrm{~m}$-cu arising from distal half of areolet, sometimes at, or rarely distad, extreme apex. Hind wing with 1 st abscissa of Cu1 $0.35-0.55$ times length of cu-a; cu-a strongly reclivous.

Metasoma. Petiole (Figs 45, 46) with S1 not extending to level of spiracle. Apical $0.5-0.6$ of postpetiole (posteriad spiracle) punctate and setose. T2 densely punctate and short setose over posterior 0.5 , with impunctate, bare, transverse line or ellipsoid medially, setose with weaker punctation anteriorly except bare and impunctate along 


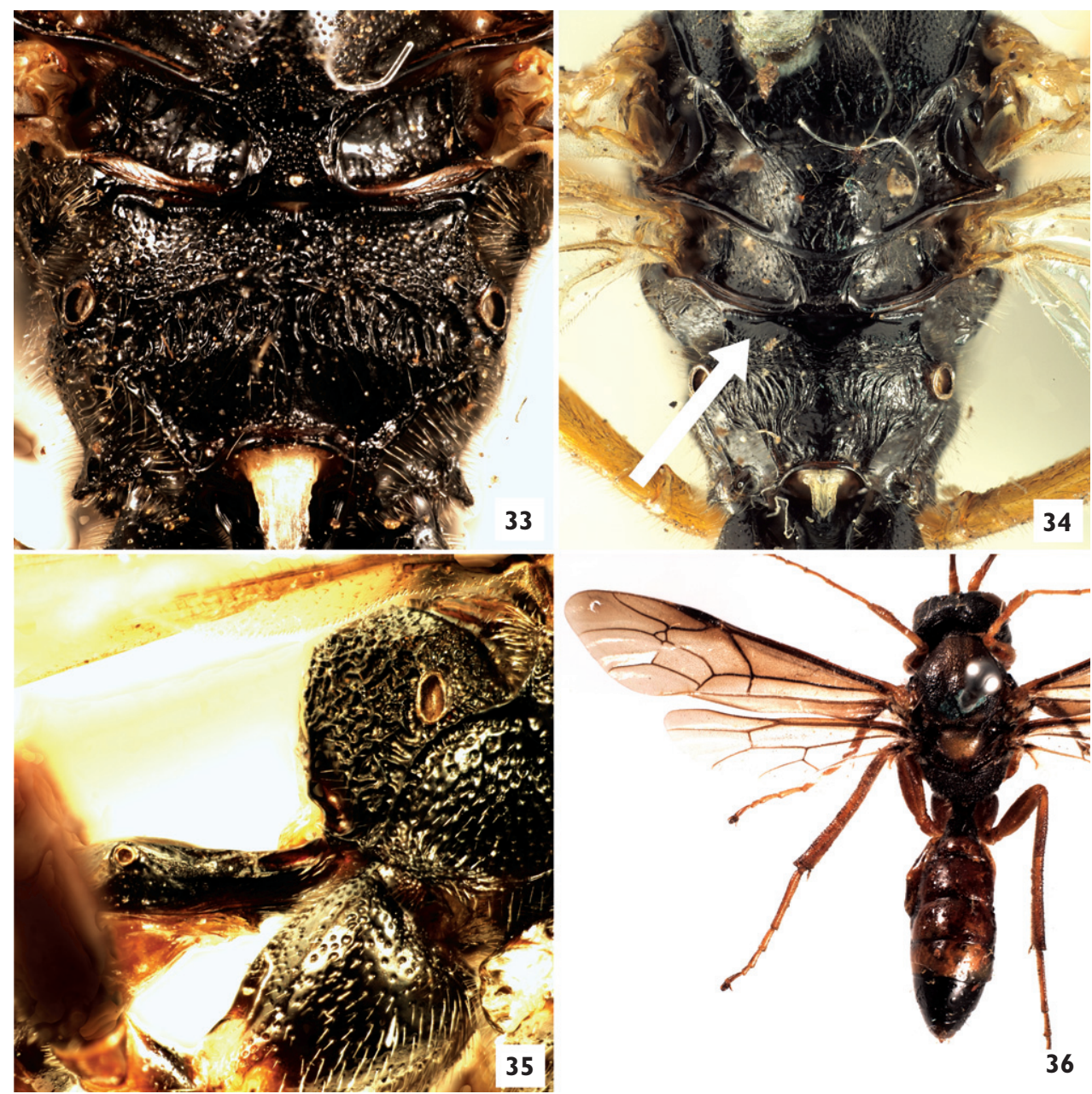

Figures 33-36. 33-34. Pergaphaga spp., propodeum, dorsal view 33 Pergaphaga nigra Gauld, nonparatype from Duntroon 34 Pergaphaga leaski Wharton, sp. n., paratype female, arrow = polished basal area 35-36 Dictyopheltes robustus Gauld, male 35 Propodeum in profile, showing sculpture 36 Dorsal habitus showing wing venation.

anterior margin. T3 and T4 often uniformly densely punctate and short-setose, occasionally with median bare, impunctate line on T3.

Color (Figs 5, 9, 13, 17, 41). Head and body black, antenna entirely black; mandibles dark basally and apically, often reddish brown medially; metasoma with petiole and terga of gaster black basally, becoming reddish brown apically in half specimens examined, posterior margin always pale yellow, with yellow markings expanded along midline on laterally compressed terga; all coxae black, trochanters and trochantelli nearly always black; femora transitioning gradually or somewhat abruptly from darker ventrally to paler mid dorsally as follows: from dark brown ventrally and orange brown dorsally to orange ventrally and yellow orange dorsally, rarely uniformly colored, fore and mid 

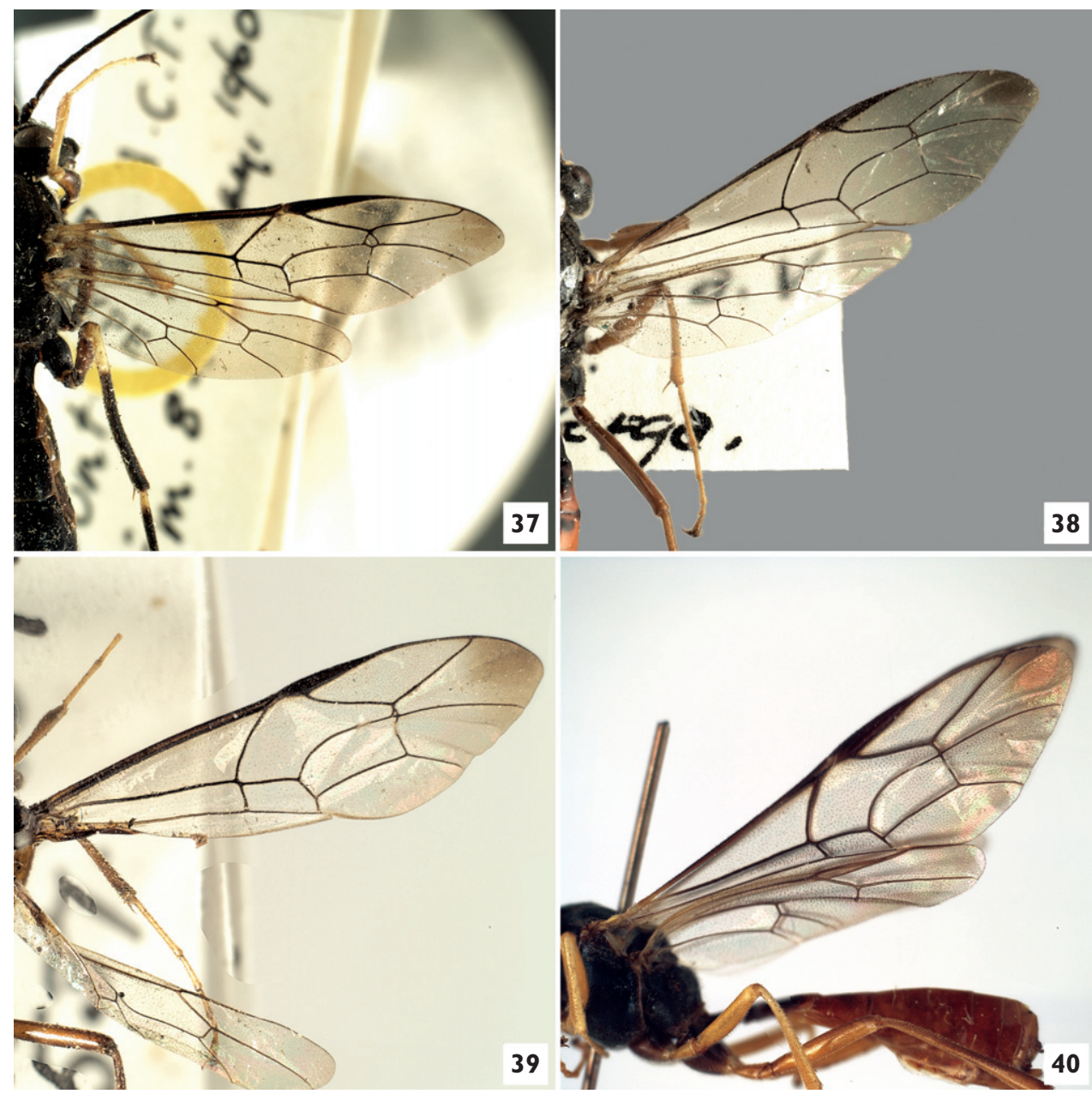

Figures 37-40. Pergaphaga spp., fore wing. 37 Pergaphaga nigra Gauld, paratype male, Duntroon 38 Pergaphaga iangauldi Cammack and Wharton, sp. n., holotype 39 Pergaphaga leaski Wharton, sp. n., paratype female 40 Pergaphaga xanthops Wharton, sp. n., holotype.

femora yellow at extreme apex; fore and mid tibiae and tarsi mostly pale yellow, with orange stripe ventrally on tibiae expanding dorsally towards apex; apical tarsomeres of all legs dark brown to black dorsally with pale spot at extreme apex; hind tibia varying from black to dark orange dorsally, with basal $0.2-0.3$ pale yellow, yellow extending along ventral midline over basal 0.5 , ventral midline varying from orange to black over distal 0.5; hind tarsi dark reddish brown to black with basitarsus yellow over basal 0.2-0.3.

Male. Essentially as in female except as follows: Hind basitarsus often slightly narrower, 8.5-10.0 times longer than wide; terminal segments of gaster not as laterally compressed; fore trochanter more frequently (30\%) brownish than in female.

Distribution and biology. This species is known only from southeastern Australia, with the known range of this species extending from South Australia through 


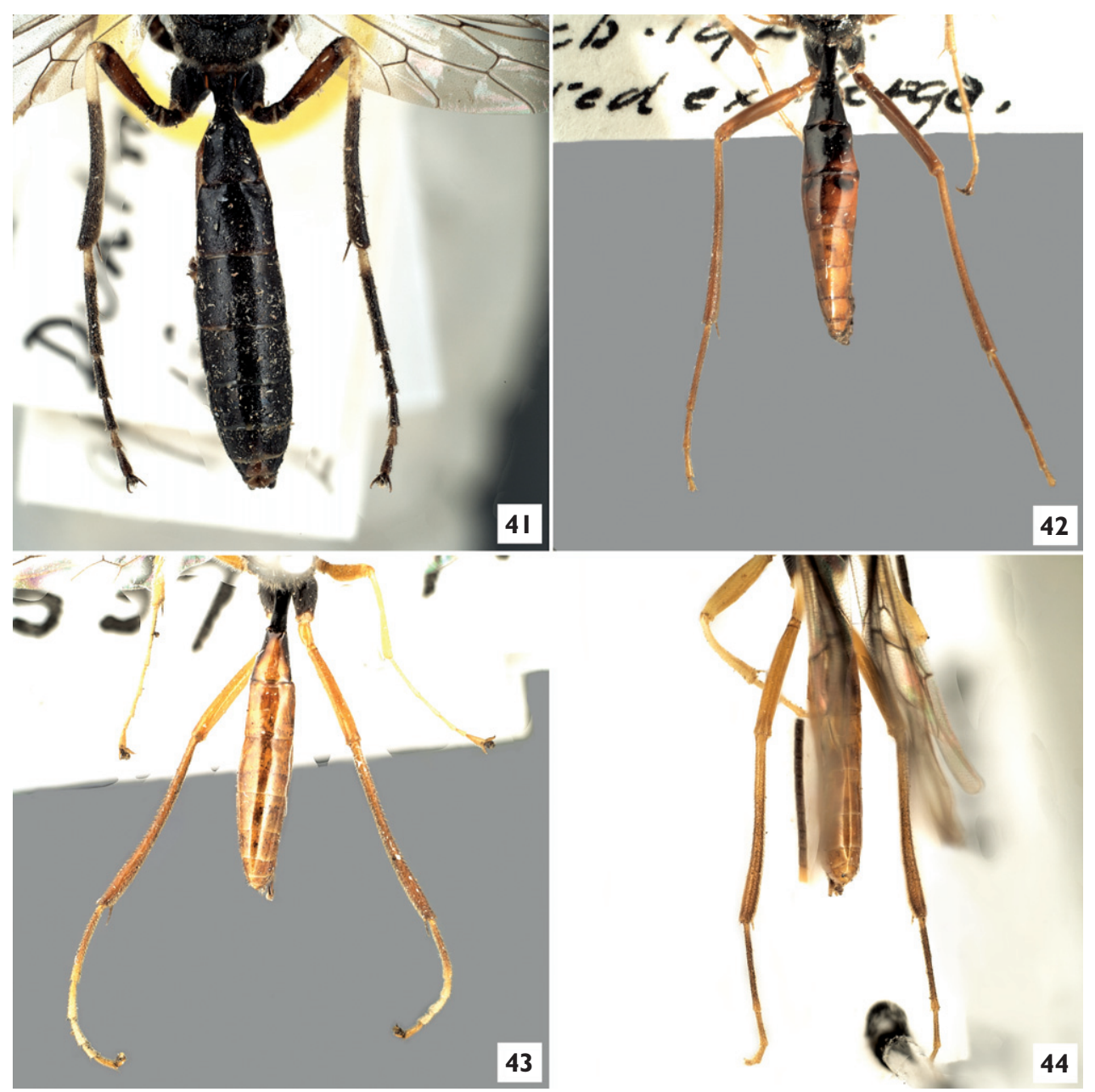

Figures 4I-44. Pergaphaga spp., metasoma and leg coloration. 4 I Pergaphaga nigra Gauld, paratype male, Duntroon 42 Pergaphaga iangauldi Cammack and Wharton, sp. n., holotype 43 Pergaphaga leaski Wharton, sp. n., holotype. 44 Pergaphaga xanthops Wharton, sp. n., holotype.

Victoria and New South Wales, coincident with the primary range of its host (Carne 1969, Schmidt and Smith 2006), Perga affinis. Unfortunately, the only specimens from South Australia (the two paratypes noted above) lack specific locality data. Collection and emergence dates for $P$. nigra range primarily from February through June, with one specimen each collected in January, July, August, and October. Based on material reared from $P$. affinis in ANIC, the specimens mentioned by Carne (1969) as an undescribed species of "?Hypopheltes," are Pergaphaga nigra. Carne (1969) provides additional information on the host, which is active during winter, and Gauld (1984) also noted that most specimens of $P$. nigra that he examined were taken late in the season.

Diagnosis. Pergaphaga nigra differs in several respects from the three new species described below. It is readily recognized by its dark coloration and distinctively 


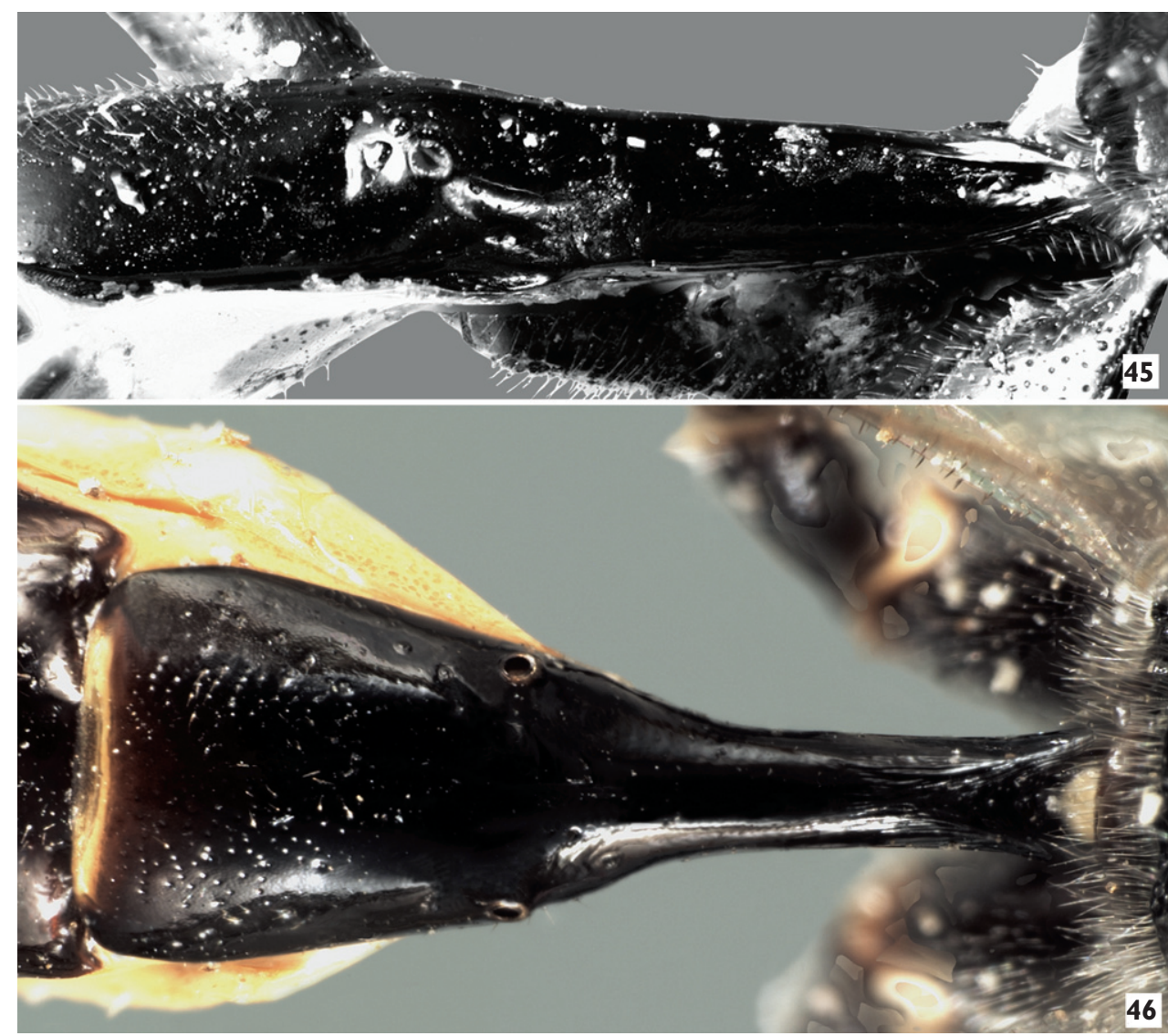

Figures 45-46. Pergaphaga nigra Gauld, petiole 45 Lateral, showing weak glymma near base $\mathbf{4 6}$ Dorsal, non-paratype from Duntroon.

bicolored hind tibia and basitarsus. Unlike the other three species, the face is entirely black and the gastral terga are black with pale apical margins. The hind basitarsus is also shorter and broader in female $P$. nigra, the fore wing areolet is larger, and the propodeum more heavily sculptured, with a distinct transverse carina at the level of the spiracles. As in P. xanthops, there is an elevated, Y-shaped flange extending between the antenna.

Remarks. The male specimen from Duntroon listed above as a paratype has a paratype label and an Ian Gauld det. label, but does not exactly match the information on paratypes provided in Gauld's (1984) original description. The specimen from Cookardinia, though listed by Gauld as a paratype, lacks a paratype label. Handwritten labels correctly give R.S. for initials of McInnes, but those typed labels with emergence dates of 1973 incorrectly give initials as R.B. Gauld (1984) lists an additional 10 female and 10 male paratypes from Murrumbateman (ANIC) that we did not see. Gauld also noted that one of the paratypes from Avoca bears a label indicating that it was the specimen figured by Townes (1970) as Megaceria. 


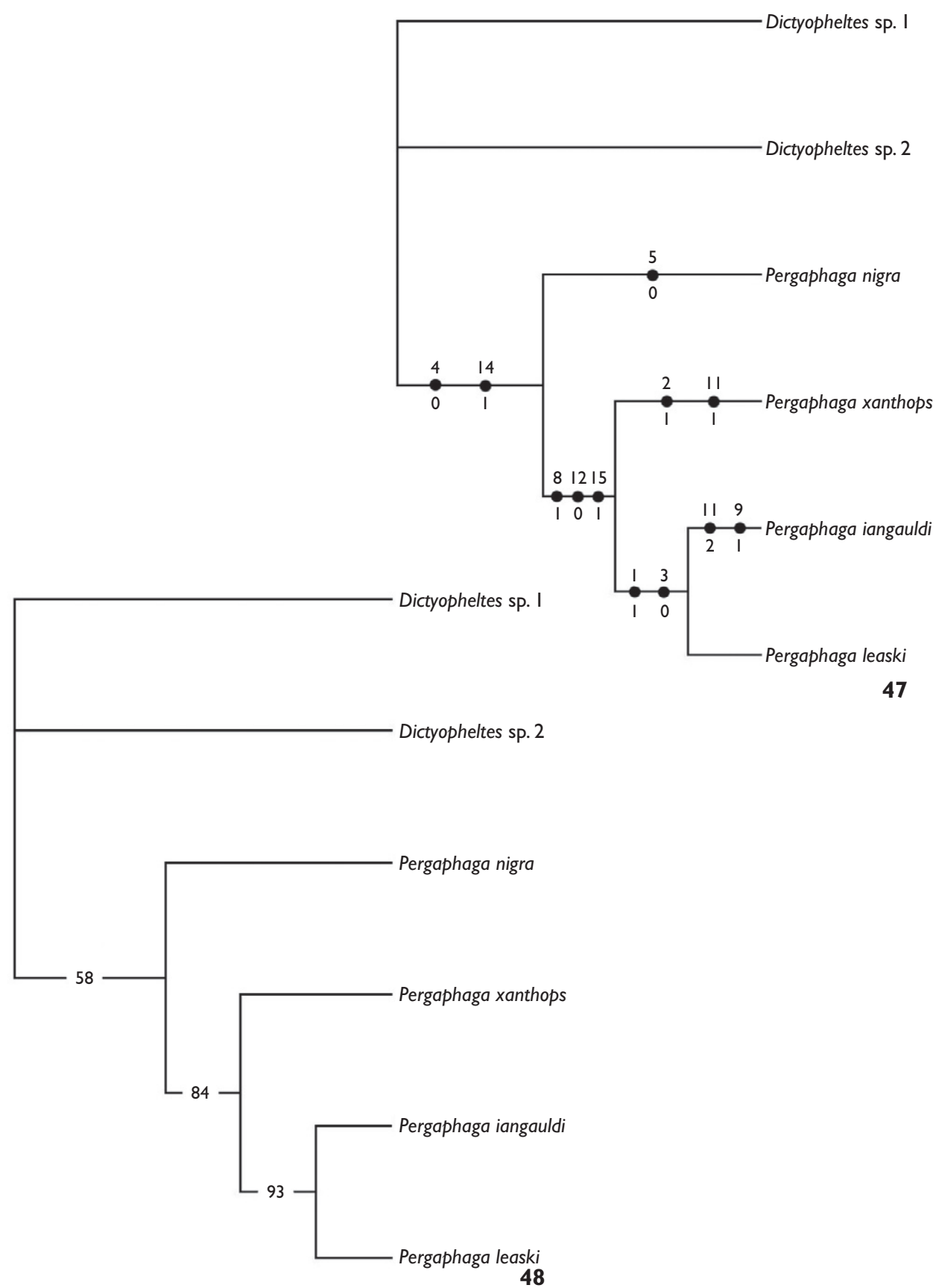

Figures 47-48. Results of parsimony-based phylogenetic analysis, generated from WinClada, producing single tree of length 21 . Branches with no unambiguous state changes are collapsed. 47 Unambiguous state changes mapped onto tree as dark circles $\mathbf{4 8}$ Same tree, showing bootstrap support values, 200 replicates, 10 searches per replicate. 
Observed variation was as great within populations as between them. Sculpture of the median part of the face varied from rugose punctate to more densely granular rugose and the hind tibia varied from black to orange in both Duntroon and Murrumbateman series. The female specimen from Duntroon shown in Fig. 5 illustrates the maximum extent of pale coloration on the apical margins of the terga among the material available for study. In one of the 10 females measured, the hind basitarsus was 10.0 times longer than wide; in one of the nine males examined, the areolet was not petiolate.

In addition to a generally more heavily sculptured propodeum relative to other species of Pergaphaga, P. nigra has the anterior transverse propodeal carina not only better developed but also generally more posteriorly displaced.

\section{Pergaphaga iangauldi Cammack \& Wharton, sp.n.}

urn:lsid:zoobank.org:act:0D8E1628-A583-4E9C-8BCC-FE1E25F2DB9A

Figs 3, 4, 6, 10, 14-16, 18, 23, 32, 38, 42

Type locality. Australia, Victoria, Murrumbeena, -37.900S, 145.067E

Type material. Holotype. Female (MVMA), with labels as follows: "Murrumbeena. V./ Feb. 1948./ Bred ex Perga." [handwritten] "Collection/ A. N. Burns" [printed] "ENT - 935" [printed] "MUS. VIC./ ENT-1089" [printed] "HOLOTYPE/ Pergaphaga/ iangauldi/ Cammack \& Wharton" [red, handwritten]

Paratypes: 3 females, 2 males, same data as holotype, one of these with an additional Certonotus identification label (MVMA); 1 female, New South Wales, Windsor, Bred by B. A. Hill, 29.XII.97, Ex. Coll. Nat. Mus. (MVMA); 1 female, ACT, Canberra, The Pinnacle, Hawker, 35 $16^{\prime}$ S, $149^{\circ} 02^{\prime} \mathrm{E}$, 6-23.X.2002, K.P. Bland (ANIC).

Other specimen examined (not a paratype): 1 female, Victoria, Bright, H.W. Davey (QMBA).

Description. Female (Fig. 6, 10). Length of body (exclusive of antenna) 13.5$16.0 \mathrm{~mm}$; of fore wing $13.7-15.0 \mathrm{~mm}$; of antenna $16.5-17.0 \mathrm{~mm}$.

Head. Clypeus (Fig. 18) 2.6-2.7 times as broad as long; weakly and uniformly convex to nearly flat in profile, very weakly thickened along lateral margin; ventral margin broadly truncate to very weakly concave, very slightly thickened; surface punctate on weakly shagreened background, punctures deep, separated from one another by their diameter; epistomal sulcus weak medially but distinct. Malar space 0.45-0.55 times basal width of mandible, strongly shagreened to finely granular-matt/punctate. Lower gena punctate, with punctures separated by $0.5-1.0$ times their diameter, usually weakly shagreened, upper gena more polished and very slightly more sparsely punctate except more densely punctate along occipital carina. Face (Fig. 18) deeply and densely punctate, varying from punctate and weakly shagreened to more densely granular punctate medially, surface distinctly undulating transversely, elevated medially and laterally, distinctly depressed near ventrolateral margin of toruli, convex between anterior tentorial pit and eye (Fig 16). Frons lacking distinctly elevated interantennal flange of $P$. nigra, 
with at most a low, very short, weak, median carina (Fig. 23); frons distinctly elevated adjacent eye, the elevated area punctate and somewhat crescent-shaped, frons otherwise flat with post-antennal area adjacent elevated lateral margin appearing weakly concave; surface often polished immediately behind scape, finely matt punctate posteriorly between posterior ocelli and eye, otherwise variously rugulose to rugose to densely granular. Antenna with 42-44 flagellomeres; first flagellomere at most 1.2 times longer than second, 3.6-3.7 times longer than wide, second flagellomere 2.8-3.1 times longer than wide, tenth 2.0-2.2 times longer than wide; tyloid of first flagellomere (Figs 14, 15) large, oval, extending $0.30-0.35$ length of first flagellomere.

Mesosoma. Pronotum laterally densely punctate. Mesopleural depression densely punctate to weakly rugulose or strigose punctate anteroventrally, the punctures large, deep, coalescing at least in part anteriorly but usually discrete though nearly adjacent medially; rounded lobe forming anterodorsal margin of mesopleural depression with similarly large, deep punctures, but with punctures often more widely spaced. Scutellum coarsely punctate. Posteromedian plate of metanotum varying from unsculptured to nearly so, polished. Metapleuron densely punctate with additional strigose sculpture in some individuals. Propodeum varying from weakly convex to nearly flat in profile, with very narrow anterior and elongate posterior fields often differentiated; base of propodeum, on either side of median depression, smooth, polished (as in Fig. 34); pleural carina nearly always incomplete: sharply defined anteriorly, touching ventrolateral corner of propodeal spiracle, discontinuous or nearly so between spiracle and weaker posterior fragment; anterior transverse carina often poorly differentiated among narrow band of transverse strigose sculpture, though sometimes distinct as a low ridge; median basal depression margined posteriorly with what may represent the median portion of anterior transverse carina; distinctly arched lateral portion of posterior transverse carina and posterior portion of lateral longitudinal carina forming large, polished, apicolateral area (Figs 32), junction of lateral longitudinal and posterior transverse carinae not tuberculate. Hind basitarsus 12.2-14.7 times longer than wide. Fore wing areolet very small, petiolate above, the stalk equal to or longer than both length and width of areolet (Fig. 38); $2 \mathrm{~m}$-cu variable, arising from middle (rarely) to extreme apex (more commonly) of areolet. Hind wing with 1 st abscissa of $\mathrm{Cu} 10.80-0.85$ times length of cu-a; cu-a reclivous.

Metasoma. Petiole with S1 not extending to level of spiracle. Postpetiole and T2-4 polished, almost completely bare and impunctate, with a few scattered punctures and setae, the latter concentrated laterally.

Color (Figs 6, 10, 16, 18, 42). Mostly black; mandible (except dark apical teeth), broad orbital bands on face extending onto anterior part of frons, clypeus (except small, irregular dark spot dorsomedially) and variously sized spot on lower gena bright yellow; scape, pedicel, and basal 19-21 flagellomeres, tegula, legs from trochanter to apex, and most of gaster orange, with fore and mid legs often yellow orange; petiole completely, T2 extensively (holotype) to completely and base of T3 at least partially black in 3 specimens; gaster completely orange and petiole with irregular orange markings posteriorly in 2 specimens. 
Male. Essentially as in female except as follows: Antenna with 41-43 flagellomeres, first flagellomere 3.1-3.2 times longer than wide; hind wing with 1st abscissa of $\mathrm{Cu} 10.65-0.85$ times length of cu-a; anterior transverse carina less evident than in most females; terminal segments of gaster not laterally compressed; face medially and clypeus dorsomedially pale orange instead of black, basal 22-23 flagellomeres orange, coxae, especially on fore leg, partly orange, gaster almost completely black in one specimen, almost completely orange in the other.

Distribution and biology. Known only from Victoria, ACT, and central New South Wales. Reared from an undetermined species of Perga (based on label data).

Diagnosis. This species is most readily recognized by the distinctively bicolored antenna, which is pale basally and dark apically. Pergaphaga xanthops also has bicolored antennae, but the pattern is reversed. Pergaphaga iangauldi lacks the elevated median flange on the frons as found in $P$. nigra and $P$. xanthops, and is thus more similar to $P$. leaski in this regard. In addition to differences in antennal color pattern, $P$. iangauldi has a more heavily sculptured mesopleuron than P. leaski.

Remarks. The female specimen from Bright is larger than members of the type series, with 46 flagellomeres, the first 30 of which are orange. The fore wing areolet is also distinctly larger (roughly intermediate in size between that of $P$. nigra and those from the type series of $P$. iangauldi), and the metapleuron is distinctly strigose in this specimen. Although considered a member of this species, it is not included as a paratype because of this variation. The following additional variation was noted among members of the type series: in one female, the flagellum is brown basally rather than orange, the epicnemial carina does not extend dorsally to the level of the ventral corner of the pronotum in several specimens, and in the left wing of one of the females, $\mathrm{Cu} 1$ is 1.15 times longer than cu-a. The female paratype from Canberra has a slightly different color pattern than the series from Murrumbeena, but unlike the specimen from Bright, sculpture and venation are the same and it is therefore included in the paratype series to emphasize color variation in this species. In the Canberra specimen, all terga of the gaster are black medially, face and clypeus are brownish yellow medially, fore and mid coxae are orange ventrally, and first 32 flagellomeres are orange.

One male specimen lacks a fore wing areolet in both wings. In the left wing, it is easier to see that that the absence of an areolet is due to the fusion of 2rs-m and 3rs-m rather than the loss of one or the other of these. This suggests that within Pergaphaga, at least, there is a trend toward gradual loss of the areolet through reduction in size and fusion of the adjacent cross veins.

The first two labels on the paratype from Windsor are handwritten. The first is difficult to read, with the month, day, and locality legible, but the remainder difficult to decipher and possibly misinterpreted. The second label is completely illegible. This and the specimen from Bright bear Pergaphaga det. labels by I. D. Gauld dated 1984.

The paratype from Canberra is also the voucher specimen for the Pergaphaga sequence reported in Quicke et al. (2009).

This species is named for Ian Gauld for his significant contribution to the understanding of this genus and the Westwoodiini in general. 


\section{Pergaphaga leaski Wharton, sp.n.}

urn:lsid:zoobank.org:act:20C7D974-B61E-4870-879A-EA0F7D055435

Figs 7, 11, 19, 26, 34, 39, 43

Type locality. Australia, Victoria, Ballarat, $-37.567 \mathrm{~S}, 143.850 \mathrm{E}$

Type material. Holotype. Female (BMNH), with handwritten labels as follows: "Bred. from. larvae./ 25-iv-1959/ No. 537. P." "Australia./ Victoria./ Ballarat./ M.F. Leask." "Glen. Park. S.F./ at. Wayne’s./ Sawfly/larvae." "adult.recog. Leask./ pergagrapta §/gravenhorstii/ Westwood.1880" "Pergaphaga/ det. I.D. Gauld, 1984” [partially printed] "HOLOTYPE/ Pergaphaga/ leaski/ Wharton" [red, handwritten]

Paratypes: 2 females, same data as holotype $(\mathrm{BMNH}) ; 1$ female, 1 male, same data except 1.VII.1959 and without Glen Park label. All paratypes have an additional British Museum 1959-460 accession label.

Description. Female (Figs 7, 11). Length of body (exclusive of antenna) $10.7 \mathrm{~mm}$; of fore wing $10.2-11.9 \mathrm{~mm}$; of antenna $12.5-14.8 \mathrm{~mm}$.

Head. Clypeus (Fig. 19) 2.7 times as broad as long; weakly and evenly convex in profile, very weakly thickened at lateral margin; ventral margin broadly truncate, slightly thickened; surface punctate on weakly shagreened background, punctures separated from one another by their diameter; epistomal sulcus distinct. Malar space $0.45-0.50$ times basal width of mandible, granular-matt. Gena as in P. iangauldi, distinctly punctate. Face (Fig. 19) deeply and densely punctate laterally, granular rugose medially, surface distinctly undulating as in $P$. iangauldi. Frons lacking distinctly elevated interantennal flange of $P$. nigra (Figs 23, 26), with a low short, weak, median carina; frons distinctly elevated adjacent eye, elevated area punctate, frons otherwise flat; surface polished immediately behind scape, densely granular on flat portion between ocellar field and eye. Antenna with 39-41 flagellomeres; first flagellomere 1.2 times longer than second, 3.3-3.6 times longer than wide, second flagellomere 2.8-3.0 times longer than wide, tenth 2.0-2.6 times longer than wide; tyloid of first flagellomere large, oval, extending 0.35-0.40 length of first flagellomere.

Mesosoma. Pronotum punctate laterally on shagreened background, punctation slightly less dense than in P. nigra and P. iangauldi, punctures separated by $1.0-1.5$ times their diameter. Mesopleural depression more sparsely punctate ventrally than in $P$. nigra and $P$. iangauldi, punctures widely separated, not coalescing medially to form either strigose or rugulose sculpture; rounded lobe forming anterodorsal margin of mesopleural depression with similarly large, well-spaced punctures. Scutellum slightly more finely punctate than in $P$. nigra and $P$. iangauldi. Posteromedian plate of metanotum polished, varying from distinctly punctate anteriorly to sparsely, indistinctly punctate throughout. Metapleuron medially finely granular-matt and sometimes weakly punctate. Propodeum weakly convex in profile, anterior and posterior fields not differentiated; base of propodeum, on either side of median depression, smooth, polished (Fig. 34); pleural carina incomplete: sharply defined anteriorly, extending to propodeal spiracle, usually absent posteriorly; anterior transverse carina not distinguishable from surrounding narrow band of transverse ridges; distinctly arched 
lateral portion of posterior transverse carina and posterior portion of lateral longitudinal carina forming apicolateral area similar to but usually weaker than in P. iangauldi, junction of lateral longitudinal and posterior transverse carinae not tuberculate. Hind basitarsus 10.6-12.0 times longer than wide. Fore wing areolet very small, triangular, petiolate above, the stalk equal to length and longer than width of areolet (Fig. 39); $2 \mathrm{~m}-\mathrm{cu}$ arising near but distad middle. Hind wing with 1 st abscissa of Cu1 0.75-0.85 times length of $\mathrm{cu}-\mathrm{a}$; $\mathrm{cu}-\mathrm{a}$ reclivous.

Metasoma. Petiole with S1 extending to level of spiracle. Apical 0.3-0.4 of postpetiole (posteriad spiracle) sparsely punctate and setose. T2 mostly bare and polished, with a few scattered punctures and a patch of short setae posterolaterally. T3 and T4 extensively setose and very faintly punctate, T4 somewhat uniformly setose, T3 decidedly less so, especially posteromedially.

Color (Figs 7, 11, 19, 43). Mostly black, antenna dark brown to black; mandible (except dark apical teeth), broad orbital bands on face extending onto anterior part of frons, at least lateral corners of clypeus, lower gena, tibia and tarsi of fore and mid legs, and tarsomeres 2-4 of hind legs bright yellow; tegula, trochanters, trochantelli, and femora of fore and mid legs darker yellow; trochanter, trochantellus, femur, and apical tarsomere of hind leg orange, hind tibia orange brown basally becoming orange over distal 0.25 , hind basitarsus orange brown basally, yellow over distal 0.25 ; postpetiole, except along lateral margins, and entire gaster orange; middle of gena with small, dark reddish brown spot posteriorly.

Male. About as in female, but only known specimen in poor condition.

Distribution and biology. Known from a single series of specimens reared from Pergagrapta gravenhorstii (Westwood) in Ballarat, Victoria.

Diagnosis. This species is readily recognized by the combination of orange gaster and entirely dark antenna. As in the larger-bodied $P$. iangauldi, an elevated median flange is absent on the frons. As noted above, P. iangauldi also has a more heavily sculptured mesopleuron than P. leaski.

Remarks. There is some minor variation in color in the type series. The clypeus is mostly reddish brown in the holotype but extensively yellow in the paratypes, with a small reddish brown spot dorsomedially.

The species is named for Maurice Leask, who reared numerous westwoodiines from various pergid sawflies, including all of the members of the type series. This species is referred to as Pergaphaga sp. 1 in Gauld (1984).

\section{Pergaphaga xanthops Wharton, sp.n.}

urn:lsid:zoobank.org:act:63AFE351-ADC6-48FF-A095-93601A1D9691

Figs $8,12,20,22,25,30,40,44$

Type locality. Australia, ACT, Canberra, -35.283S, 149.217E

Type material. Holotype. Female (ANIC), with labels as follows: "Canberra ACT/ 11 Apr 1958/ E F Riek" [printed] "Pergaphaga/ det. I.D. Gauld, 198” [partially printed] "HOLOTYPE / Pergaphaga/ xanthops/ Wharton" [red, handwritten] 
Paratypes: 1 female, same data as holotype except 15.IV.1958 (BMNH); 1 male, New South Wales, Dainers Gap, 36.12S, 148.43E, 1585 m, 6.III.1974, P Morrow, Eucalyptus pauciflora, stellulata, and perriniana forest, Ex Eucalyptus pauciflora (ANIC).

Description. Female (Figs 8, 12). Length of body (exclusive of antenna) 10.7$11.0 \mathrm{~mm}$; of fore wing $9.7-10.5 \mathrm{~mm}$; of antenna $12.0-12.8 \mathrm{~mm}$.

Head. Clypeus (Fig. 20) 2.5-2.6 times as broad as long; weakly and uniformly convex to nearly flat in profile; ventral margin broadly truncate to very weakly concave, broadly but weakly thickened medially; surface punctate on weakly shagreened background, punctures deep, separated from one another by their diameter dorsally, nearly coalescing ventrally; epistomal sulcus distinct. Malar space $0.40-0.45$ times basal width of mandible, shagreened or polished, punctate near mandible, weakly granular near eye. Gena weakly to distinctly shagreened and punctate ventrally, polished or nearly so dorsally, punctures separated by $0.5-1.0$ times their diameter ventrally, more finely punctate dorsally with punctures 1-2 times their diameter. Face (Fig. 20) deeply punctate laterally, densely granular punctate to granular rugose medially, surface very slightly undulating transversely, weakly elevated medially, weakly depressed near ventrolateral margin of toruli, nearly flat between anterior tentorial pit and eye. Frons with median flange (Fig. 22) extending posteriorly beyond posterior margin of toruli, indistinctly bifurcating posteriorly, the resulting depressions between flange and toruli polished; frons rugose between posterior end of flange and median ocellus, strigose and finely granular to partly polished on flattened portion between ocellar field and eye, punctate on weakly elevated portion between antenna and eye. Antennal flagellum with 36 flagellomeres; first flagellomere 1.1 times longer than second, 3.1 times longer than wide, second flagellomere 2.6 times longer than wide, tenth 2.2 times longer than wide; tyloid of first flagellomere large, oval, extending 0.4 length of first flagellomere.

Mesosoma. Pronotum laterally densely punctate around margins, finely granularmatt to granular rugulose medially. Mesopleural depression more densely punctate ventrally (Fig. 30) than in $P$. leaski, but punctures discrete, not coalesing to form either strigose or rugulose sculpture as in P. nigra, and anteroventrally as in P. iangaul$d i$; rounded lobe forming anterodorsal margin of mesopleural depression very finely, densely punctate, the punctures discrete but often touching or nearly so. Scutellum finely punctate. Posteromedian plate of metanotum sparsely punctate, polished. Metapleuron medially granular-matt. Propodeum weakly convex in profile, anterior and posterior fields very weakly differentiated; base of propodeum, on either side of median depression, smooth, polished (as in Fig. 34); pleural carina incomplete in one specimen, complete in the other: sharply defined anteriorly, extending to propodeal spiracle, absent or very weak posteriorly; anterior transverse carina not readily distinguishable within band of transversely strigose sculpture; posterior portion of lateral longitudinal carina arched medially to form nearly complete apicolateral area with portions of posterior transverse carina, junction of lateral longitudinal and posterior transverse carinae not tuberculate. Hind basitarsus 11.6-14.0 times longer than wide. Fore wing areolet absent (Fig. 40). Hind wing with 1st abscissa of Cu1 0.70 times length of cu-a; cu-a reclivous. 
Metasoma. Petiole with S1 almost extending to level of spiracle. Apical 0.5 of postpetiole (posteriad spiracle) sparsely punctate and setose. T2-4 very faintly punctate; T2 setose throughout, T3 and T4 with a few, scattered setae medially, sparsely setose laterally.

Color (Figs 8, 12, 20, 44). Mostly dark brown to black; mandible (except dark apical teeth), face (except small triangle extending anteriorly from between antennae), clypeus, malar space, broad band on gena adjacent eye, fore and mid legs (except coxae and apical tarsomere), and subapical flagellomeres 19-31 bright yellow; mid and hind coxae dark brown dorsally, brown ventrally, fore coxa partly yellow ventrally; hind legs distad coxa light yellow brown, a little darker dorsally, with hind basitarsus and apical tarsomeres on all legs a little darker; gaster and apical margin of petiole orange.

Male. Essentially as in female except as follows: Clypeus punctate, polished, without shagreened sculpture; antenna with 39 flagellomeres; face with black vertical band, the band narrower than adjacent yellow orbital bands; frons more polished, with less extensive rugose sculpture medially between median ocellus and most elevated portion of flange; apical flagellomere weakly infumate, otherwise yellow from flagellomere 19 to apex.

Distribution and biology. Australia; known only from ACT and a nearby locality in NSW. Eucalyptus pauciflora is listed on the label as the host plant for the male paratype from NSW. Morrow et al. (1976) collected four species of Perginae (Pergidae), representing four different genera, from this plant host at this locality. It is unclear from the label data whether this specimen was reared or simply collected from this plant, but no parasitoid rearings were indicated in Morrow et al. (1976).

Diagnosis. This species is readily recognized by the absence of a fore wing areolet and the bicolored antenna which is dark basally and pale apically/subapically. As in $P$. nigra and unlike the other two species, there is an elevated, Y-shaped flange extending between the antenna and onto the frons in P. xanthops.

Remarks. The apical teeth of the mandible are slightly shorter and more bluntly rounded in this species relative to the other three. This may be due to wear, however, as indicated by slight variation in size and shape of the teeth in the longer series of $P$. nigra available for study. Additionally, the epipleura are not as fleshy in appearance in this species as they are in P. nigra and P. iangauldi. It is difficult to determine whether this is a true difference or a preservation artifact. The epicnemial carina is also weaker in this species than in the other three, and the dorsal extent is particularly difficult to discern. The clypeus appears somewhat different in shape when Fig. 20 is compared to the figures of the other three species shown on the same plate. This is almost entirely due to the angle of view, with the face angled more ventrally in Fig. 20.

The underlying sculpture of the female paratype is not as finely granular or shagreened as it is in the holotype. This is especially noticeable on the malar space, lower gena and area extending between the eye and ocellar field.

The species name is in reference to the extensively yellow face of the females. 


\section{Acknowledgements}

This work would not have been possible without the groundwork provided by Ian Gauld's study of the Australian fauna, including the initial recognition of the new species described here. We are particularly grateful for his assistance in many aspects of this study. We also thank the following curators and researchers for extended loans of the material used for this revision: John LaSalle (ANIC), Ian Gauld (deceased) and Gavin Broad (BMNH), Ken Walker (MVMA), and Chris Burwell (QMBA). Donald Quicke also kindly sent us the specimen he sequenced as part of his study on the molecular phylogeny of Ichneumonidae. We thank David Wahl of the American Entomological Institute (AEIC) for permission to use material previously published in the Contributions of the American Entomological Institute, as well as for useful feedback throughout our study of Westwoodiini. Figs 1 and 2 were scanned and recaptioned from original illustrations that were used in Townes (1969) Memoirs of the American Entomological Institute, vol. 13, with permission of the AEIC. Matt Yoder provided considerable assistance with databasing issues and help with references to the HAO. The previously published images of Pergaphaga nigra were taken mostly by Kira Zhaurova, and the Texas A\&M MIC is gratefully acknowledged for use of the SEM equipment; Heather Cummins generously assisted us with image processing, formatting, and literature retrieval; Aubrey Colvin and Ana DalMolin assisted with the analyses. This revision is based upon work supported by the National Science Foundation's PEET program under Grant No. DEB 0328922 and associated REU supplement nos DEB 0723663 and DEB 0522836. The HAO is funded by NSF DBI 0850223 to Andy Deans at North Carolina State University.

\section{References}

Carne PB (1969) On the population dynamics of the eucalypt-defoliating sawfly Perga affinis affinis Kirby (Hymenoptera). Australian Journal of Zoology 17: 113-141.

Elliot HJ, Bashford R (1995) Notes on the biology and behaviour of eucalypt-defoliating sawflies (Hymenoptera: Pergidae) in Tasmania. Tasforests 7: 27-35.

Gauld ID (1984) An Introduction to the Ichneumonidae of Australia. British Museum (Natural History), London, 413 pp.

Gauld ID (1991) The Ichneumonidae of Costa Rica, 1. Memoirs of the American Entomological Institute 47: 1-589.

Gauld ID (1997) Tribe Scolobatini. In: Gauld, I.D. The Ichneumonidae of Costa Rica, 2. Memoirs of the American Entomological Institute 57: 187-199.

Gupta VK (1987) The Ichneumonidae of the Indo-Australian area (Hymenoptera). Memoirs of the American Entomological Institute 41(1): 1-597.

Morrow PA, Bellas TE, Eisner T (1976) Eucalyptus oils in the defensive oral discharge of Australian sawfly larvae (Hymenoptera: Pergidae). Oecologia (Berlin) 24: 193-206. 
Musen M, Shah N, Noy N, Dai B, Dorf M, Griffith N, Buntrock JD, Jonquet C, Montegut MJ, Rubin DL (2008) BioPortal: Ontologies and data resources with the click of a mouse. American Medical Informatics Association Annual Symposium Proceedings 2008: $1223-1224$.

Nixon KC (2002) WinClada ver. 1.0000 Published by the author, Ithaca, NY, USA. Retrieved from: http://www.cladistics.com/Citations.html

Quicke DLJ, Laurenne NM, Fitton MG, Broad GR (2009) A thousand and one wasps: a $28 \mathrm{~S}$ rDNA and morphological phylogeny of the Ichneumonidae (Insecta: Hymenoptera) with an investigation into alignment parameter space and elision. Journal of Natural History 43: $1305-1421$.

Schmidt S, Smith DR (2006) An annotated systematic World catalogue of the Pergidae (Hymenoptera). Contributions of the American Entomological Institute 34(3): 1-207.

Sharkey MJ, Wharton RA (1997) Morphology and terminology. In: Wharton RA, Marsh PM, Sharkey MJ (Eds) Manual of the New World Genera of the Family Braconidae (Hymenoptera). The International Society of Hymenopterists, Washington, D.C., 19-37.

Short JRT (1978) The final larval instars of the Ichneumonidae. Memoirs of the American Entomological Institute 25: 1-508.

Smith B, Ashburner M, Rosse C, Bard J, Bug W, Ceusters W, Goldberg LJ, Eilbeck K, Ireland A, Mungall CJ, the OBI Consortium, Leontis N, Rocca-Serra P, Ruttenberg A, Sansone S-A, Scheuermann RH, Shah N, Whetzel PL, Lewis S (2007) The OBO Foundry: coordinated evolution of ontologies to support biomedical data integration. Nature Biotechnology 25: 1251-1255.

Szépligeti G (1908) Hymenoptera, Braconidae und Ichneumonidae. In: Michaelson W, Hartmeyer R (Eds) Die Fauna Südwest-Australiens, 1: 317-324.

Townes H (1969) Genera of Ichneumonidae, Part 1. Memoirs of the American Entomological Institute 11: 1-300.

Townes H (1970) Genera of Ichneumonidae, Part 3. Memoirs of the American Entomological Institute 13: 1-307.

Wharton RA (2006) The species of Sternaulopius Fischer (Hymenoptera: Braconidae, Opiinae) and the braconid sternaulus. Journal of Hymenoptera Research 15: 317-347.

Wharton RA, Roeder K, Yoder MJ (2008) A monograph of the genus Westwoodia (Hymenoptera: Ichneumonidae). Zootaxa 1855: 1-40.

Yoder M, Dole K, Deans A (2006) Introducing 'mx', a sharable digital workbench for systematic biologists. Proceedings of Taxonomic Database Working Group. http://www.tdwg. org/proceedings/article/view/38/0 [accessed 1 Sept 2009]

Yoder MJ, Mikó I, Seltmann KC, Bertone MA, Deans AR. A gross anatomy ontology for Hymenoptera. Submitted to BMC Bioinformatics.

Yu D, Horstmann K (1997) A catalogue of world Ichneumonidae (Hymenoptera). Memoirs of the American Entomological Institute 58: 1-1558.

Zhaurova K, Wharton RA (2009) Recognition of Scolobatini and Westwoodiini (Hymenoptera, Ctenopelmatinae) and revision of the component genera. Contributions of the American Entomological Institute 35 (5): 1-77. 